
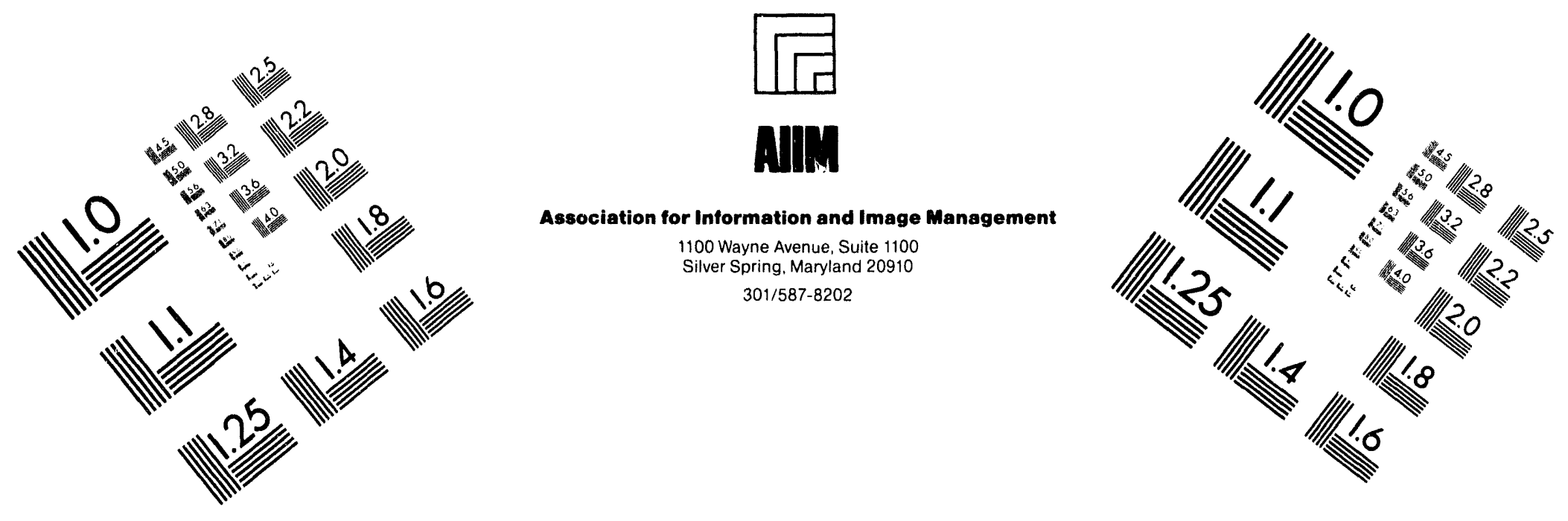

\title{
Centimeter
}

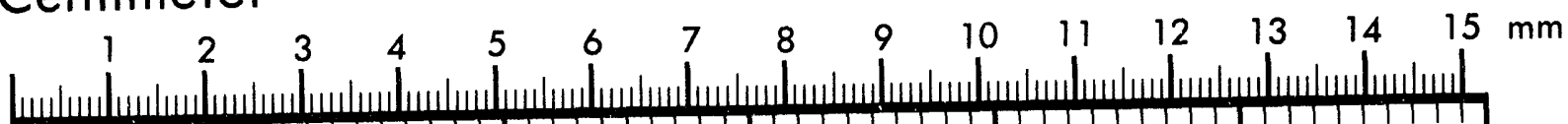
m Inches
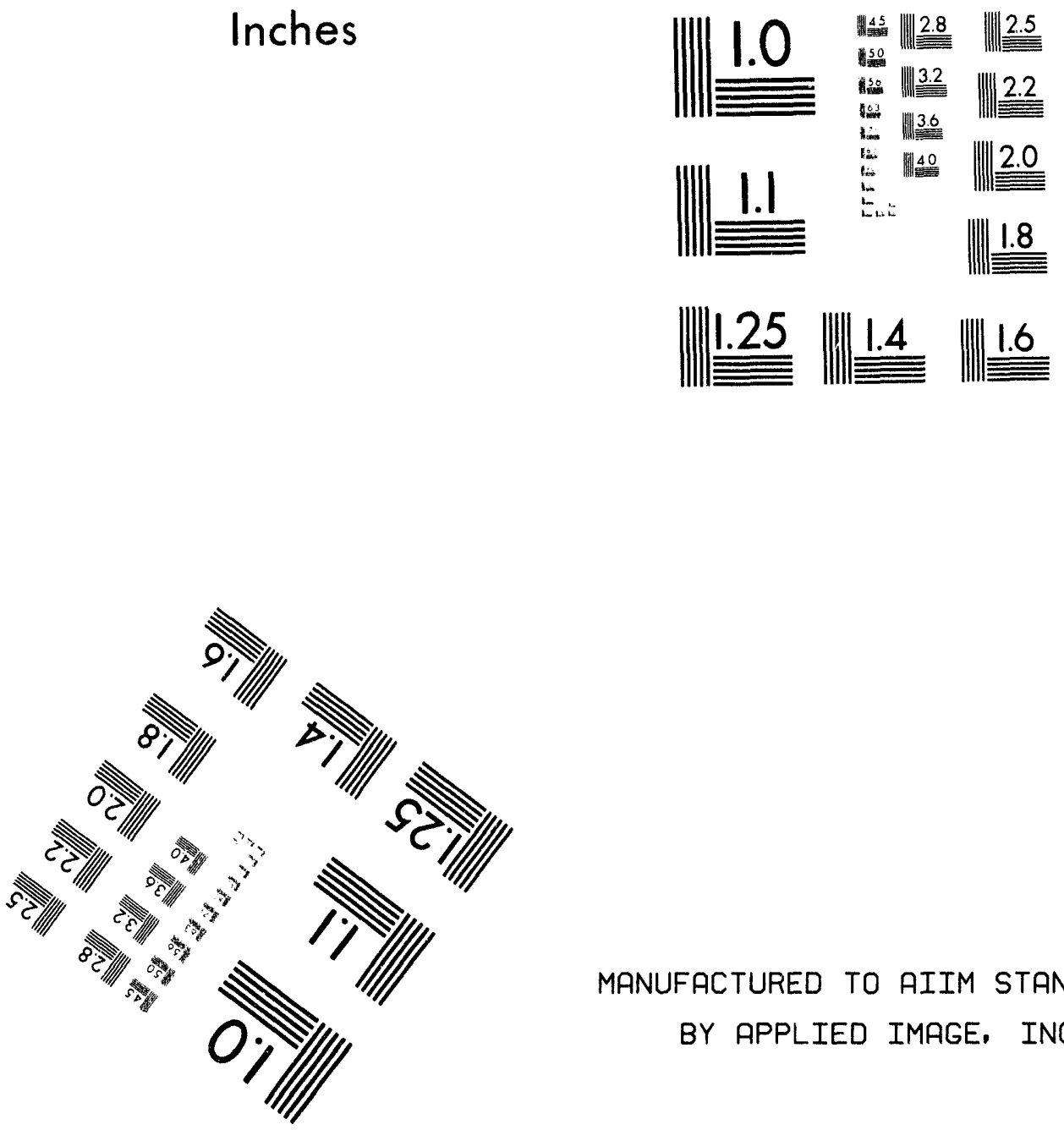

MANUFACTURED TO AIIM STANDARDS BY APPLIED IMAGE, INC.

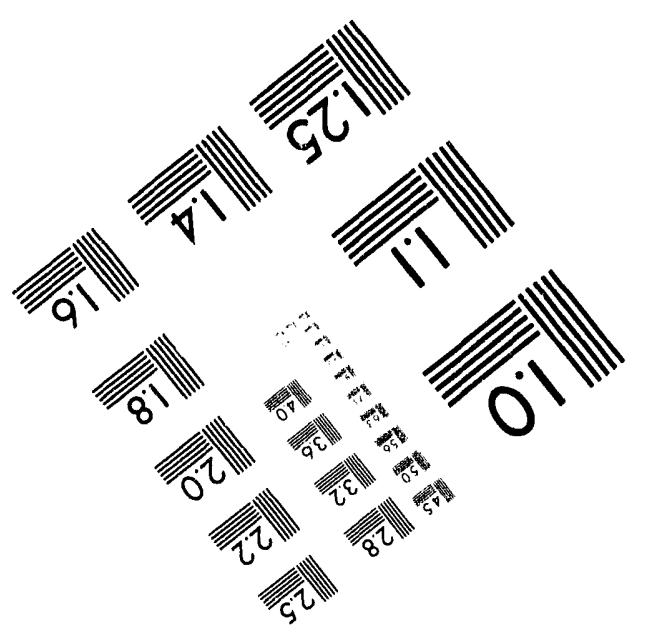



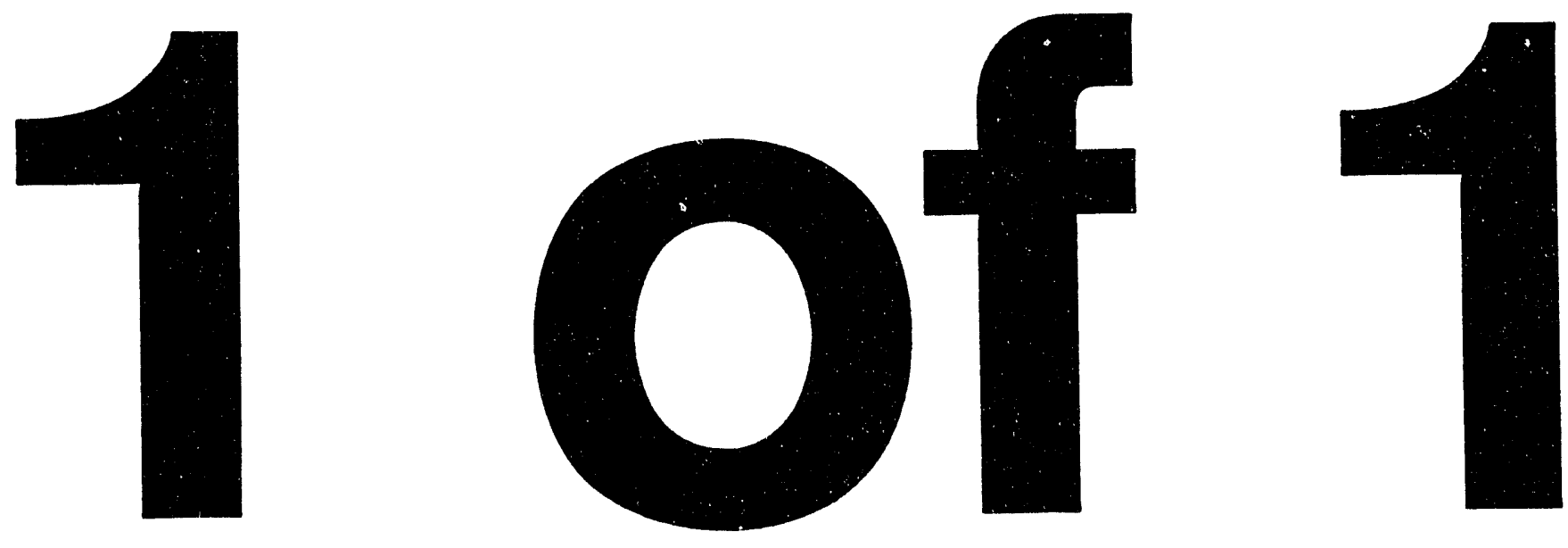
UCRL-CR-117775

S/C - B235341

Aerodynamic, Structural, and Trajectory Analysis of Astrid-1 Vehicle
L. S. Glover
A. P. Iwaskiw
M. A. Oursler
L. L. Perini
E. D. Schaefer

Februart 10, 1994

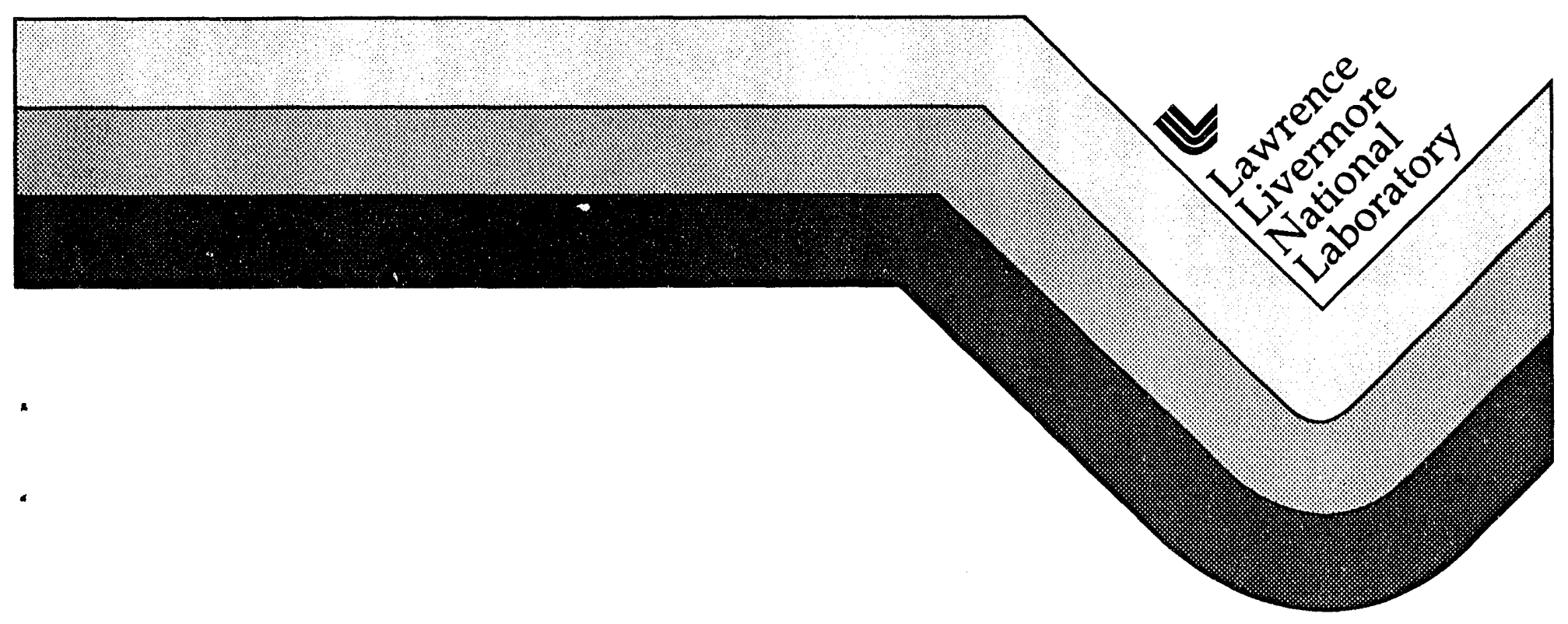


DISCLAINER

Work performed under the auspices of the U.S. Department of Energy by Lanrence Livermore National Laboratory under contract number W-7405-ENG-48.

This document was prepared as an account of work sponsored by an agency of the l'nited States Government. Neither the United States Government nor the University of California nor any of their employees, makes any warranty, express or implied, or assumes any legal liability or responsibility for the accuracy, completeness, or usefulness of any information, apparatus, product. or process disclosed, or represents that its use would not infringe privately owned rights. Reference herein to any specific commercial products, process, or service by trade name, trademark, manufacturer, or otherwise, does not necessarily constitute or imply its endorsement, recommendation, or favoring by the Inited States Government or the Lniversity of California. The views and opinions of authors expressed herein do not necessarily state or reflect those of the United States Government or the University of California. and shall not be used for advertising or product endorsement purposes. 


\section{AERODYNAMIC, STRUCTURAL, AND TRAJECTORY ANALYSIS OF ASTRID-1 VEHICLE}

\section{THE JOHNS HOPKINS UNIVERSITY THE APPLIED PHYSICS LABORATORY}

L.S. Glover, A.P. Iwaskiw, M.A. Oursler, L.L. Perini, and E.D. Schaefer

February 10, 1994 


\section{INTRODUCTION}

The Johns Hopkins University/Applied Physics Laboratory, JHU/APL, in support of Lawrence Livermore National Laboratory, LLNL, is conducting aerodynamic, trajectory, and structural analysis of the Advanced Single Stage Technology Rapid Insertion Demonstration (ASTRID) vehicle, being launched out of Vandenberg Air Force Base (VAFB) in February 1994.

The resulting analysis documented herein is for the purpose of (1) developing results to be used in generating Flight Plan Approval, FPA, and Operational Approval, OA, for the ASTRID-1 launch, Reference 1, and (2) documentation of analysis in fulfillment of the tasks assigned to The Johns Hopkins University/The Applied Physics Laboratory, JHU/APL, under contract to Lawrence Livermore National Laboratory, LLNL.

The launch is designated ASTRID-1 and is the first in a series of three that will be launched out of Vandenberg Air Force Base, VAFB. Launch dates for the next two flights have not been identified, but they are scheduled for the 1994-1995 time frame.

The primary goal of the ASTRID-1 flight is to test the LLNL light weight thrust on demand bi-propellant pumped divert propulsion system, Reference 2 . The system is employed as the main thrusters for the ASTRID-1 vehicle and uses hydrazine as the mono-propellant.

The major conclusions are:

1) The vehicle is very stable throughout flight (stability margin $=17$ to 24 inches).

2) The aerodynamic frequency and the roll rate are such that pitch-roll interactions will be small.

3) The high stability margin combined with the high launcher elevation angle makes the vehicle flight path highly sensitive to perturbations during the initial phase of flight, i.e., during the first second of flight after leaving the rail.

4) The major impact dispersions for the test flight are due to winds. The wind impact dispersions are $90 \%$ dictated by the low altitude, 0 to $1000 \mathrm{ft}$., wind conditions.

5) In order to minimize wind dispersions, head wind conditions are favored for the launch as November VAFB mean tail winds result in land impacts. The ballistic wind methodology can be employed to assess the impact points of winds at the launch site. 
6) The stress analysis indicates that the vehicle is designed with sufficient strength to endure the proposed flight.

7) Structural and aerodynamic frequencies are separated sufficiently to preclude resonance phenomena.

ASTRID-1 is a single stage liquid propellant rocket. There are no ejectables during the flight. The vehicle configuration is sketched in Figure 1. The vehicle dry weight is $8.20 \mathrm{~kg}$ (18.081 lbs). The take-off propellant weight will be dependent on the thrust level measured by a load cell at ignition. The vehicle will be loaded with $14.76 \mathrm{~kg}$ $(25.931 \mathrm{lbs})$ of propellant and for a $80 \mathrm{lb}$ thrust the launch propellant weight will be 7.60 $\mathrm{kg}(16.785 \mathrm{lbs})$ whereas for a $90 \mathrm{lb}$ thrust level the launch propellant weight will be $9.0 \mathrm{~kg}$ (19.845 lbs). The propellant loads are selected on the criteria that burnout occurs 2 to 3 seconds prior to apogee. The appropriate launch propellant load is attained by burning off propellant on the rail prior to release for take-off. The $90 \mathrm{lb}$ sea level thrust is the nominal case, whereas the $80 \mathrm{lb}$ sea level thrust represents the lower thrust value acceptable for launch. The lower value has been employed for the baseline trajectory analysis as a conservative bound for range safety. Hydrazine, $\mathrm{N}_{2} \mathrm{H}_{4}$, has a density of $1.004 \mathrm{Mg} / \mathrm{m}^{3}$ ( $\left.8.323 \mathrm{lb} / \mathrm{gal}\right)$ and the fuel load is 7.61 (2.01 gallons). Hydrazine is considered a hazard group III liquid propellant, Reference 3 . The propellant load is selected to provide a burn-out time approximately 2.77 seconds prior to apogee.

The vehicle is to be launched from a $18.29 \mathrm{~m}$ ( $60 \mathrm{ft}$ ) long rail at a $80^{\circ}$ elevation angle with a launch azimuth of $245^{\circ}$ from true north. The ASTRID-1 has four fins, that are to be canted at $1^{\circ}$, in order to attain a $23.5 \mathrm{rad} / \mathrm{sec}(3.74 \mathrm{rev} / \mathrm{s})$ roli rate to reduce dispersions. No guidance is employed on the ASTRID-1.

For the atmospheric model we have employed the VAFB Reference Atmosphere, Ref. 4, used by $30 \mathrm{SPW} / \mathrm{SEYO}$ for flight analysis and the properties (temperature, pressure, density, and sound speed as a function of altitude) are listed in Table 1.

\section{LAUNCH TOWER}

The ASTRID-1 rocket is stabilized by fins. Its low acceleration at launch requires that it be rail guided until the fins become aerodynamically effective. The launch tower and guide rail are $18.3 \mathrm{~m}$ (60 feet) long. The tower is a commercial triangular guyed radio tower, Reference 5. The guide rail is clamped to one of the legs of the tower. The tower and rail are shown in Figure 2 and are installed at a $10^{\circ}\left( \pm 1.0^{\circ}\right)$ angle from the vertical, i.e., initial elevation angle, $\gamma_{0}=80^{\circ}$. The launch is to be from launch complex LF-08 at VAFB with the following geodetic coordinates, Reference 6, based on the World Geodetic System of 1984 (WGS 84):

$\begin{array}{lc}\text { Latitude } & 34.8506^{\circ} \\ \text { Longitude } & -120.5975^{\circ} \\ \text { Geodetic height } & 2.0 \mathrm{~m}(6.57 \mathrm{ft})\end{array}$


The tower is oriented on LF-08 Launch Site to produce a $245^{\circ}\left( \pm 5^{\circ}\right.$ ) launch azimuth from true north so that the control van will be located behind the 90 degree line, References 7 and 8 .

\section{PROPULSION}

Propulsion parameters were received from LLNL, References 9 and 10, and are listed in Table 2. There are four nozzles each developing $116.72 \mathrm{~N}(26.241 \mathrm{lbs})$ of vacuum thrust at a flow rate of $0.05278 \mathrm{~kg} / \mathrm{s}(0.1164 \mathrm{lb} / \mathrm{s})$. The nozzles are tilted such that the thrust vector for each nozzle goes through the center-of-gravity (cg) at the fully loaded weight. The nozzle centerline, at the base, is located $1.79^{\prime \prime}$ radially from the ASTRID longitudinal axis and, for a fully loaded cg location of $0.931 \mathrm{~m}\left(36.65^{\prime \prime}\right)$ from the nose [body length $=1.869 \mathrm{~m}\left(73.582^{\prime \prime}\right)$ ], this gives a nozzle cant angle of $2.78^{\circ}$. The four motors develop a total baseline vacuum thrust of $F_{v a c}=466.88 \mathrm{~N}(104.963 \mathrm{lbs})$ and, for the $2.78^{\circ}$ cant angle, this yields an axial thrust of $466.32 \mathrm{~N}(104.84 \mathrm{lbs})$. The vacuum thrust level, $\mathrm{F}_{\mathrm{vac}}$, and propellant flow rate were maintained constant for the analysis, with the delivered thrust being evaluated from,

$$
\mathrm{F}_{\mathrm{del}}=\mathrm{F}_{\mathrm{vac}}-\mathrm{p}_{0} \mathrm{~A}_{\mathrm{e}}
$$

where $\mathrm{p}_{0}$ is the ambient pressure and $\mathrm{A}_{\mathrm{e}}$ is the nozzle exit area. The total baseline sea level thrust for the 4 nozzles is $355.84 \mathrm{~N}$ (80.00 lbs).

Figure 3 shows a rear view of the ASTRID-1 configuration. The six-degree-offreedom, $6 \mathrm{DOF}$, trajectory program used in the analysis employs a body reference axes system where the $x$ axis is positive out of the figure along the body longitudinal axis, the $z$ axis is positive up and the $y$ axis is positive to the right. This is in contrast to the LLNL coordinate system where the $\mathrm{x}$ axis is positive into the figure. The nozzles are in a cross configuration at launch with the north nozzle designated No. 1 and the sequence increasing in a clockwise direction.

\section{AERODYNAMICS}

Aerodynamic coefficients have been determined for the ASTRID-1 vehicle geometry for the range of Mach numbers $M=0$ to 3.0. The estimates are for the sea level condition as the effects of altitude (i.e., Reynolds Number) are not significant for the altitude range of interest, $Z=0$ to $6.10 \mathrm{~km}(20,000 \mathrm{ft})$. Shown in Table 3 are the resulting axial, normal, and side force coefficients or derivatives, the pitching, yawing, and rolling moment coefficients or derivatives, and the pitch and roll damping derivatives. ASTRID- 1 will operate at low angles of attack, $\alpha$, and sideslip angle, $\beta$, and incorporates a small tail fin incidence angle, $\delta=1^{\circ}$. Therefore, it is valid to use a linear approximation for the dependence of the coefficients on angle of attack, sideslip angle, and tail incidence angle. The axial force coefficients, $\mathrm{C}_{\mathrm{A}}$, are applicable to both the 
power-off and power-on flight phases. Testing, documented in Reference 11, indicates that, for the geometry and exhaust nozzle flow rates of the ASTRID-1 vehicle, there is essentially no change in base drag for the power-on phase of flight. Two commonly accepted computer codes were used to estimate the aerodynamic coefficients; MISSILE DATCOM, Reference 12 and NSWC DD Aerodynamic Prediction Code, APC, Reference 13. The force and moment coefficients were determined with DATCOM and the APC was employed to determine the damping derivatives. The two codes were used to provide a measure of comparison between the predictions and to take advantage of the strengths of each code. The code documentation, References 12 and 13, confirms that the ASTRID-1 geometry and flight parameters are within the applicability of both codes.

ASTRID-1 flight will occur at speeds below $\mathrm{M}=1.0$; our present interest in trajectory accuracy is in this speed regime though future flights will operate at higher speeds. Ideally, the accuracy of aerodynamic coefficients would be derived by comparison of code predictions with experimental results for a vehicle similar to the ASTRID-1 at the Mach numb irs of interest. The DATCOM and APC codes have broad applicability and this type of specific information is available in the literature only for the APC code. The general accuracy of DATCOM in the range $0<\mathrm{M}<6$ and $-20^{\circ}<\alpha<$ $30^{\circ}$ is addressed in Reference 14 . The general overall accuracy numbers in Table 3 for all items except for $C_{\mathrm{Ip}}$ and $\mathrm{C}_{\mathrm{mq}}$, were taken from Reference 14 and are applicable to the entire $\mathrm{M}$ and $\alpha$ range for the code. The general accuracy of the APC in the range 0 $<\mathrm{M}<8$ and $0^{\circ}<\alpha<180^{\circ}$ is addressed in Reference 15. Specific comparison of prediction to experiment is provided for the Basic Finner rocket which bears substantial geometric similarity to ASTRID-1. The accuracy numbers in Table 3 for the $C_{l p}$ and $\mathrm{C}_{\mathrm{mq}}$ derivatives are extracted from Reference 15 for $1<\mathrm{M}<3.0$. The reference area is based on the $0.165 \mathrm{~m}\left(6.5^{\prime \prime}\right)$ diameter, $A_{\text {ref }}=0.0214 \mathrm{~m}^{2}\left(0.2304 \mathrm{ft}^{2}\right)$. Shown in Figure 4 are the axial force contributions due to skin friction, launch lugs, base, fins and body wave (pressure) as a function of $M$. Note the large contribution of the base drag in the $\mathrm{M}<1$ range.

The fins are in a cruciform configuration, Figure 3, and at launch the north east fin is designated No.1 with the sequencing increasing in a clockwise direction.

The reference center for the moment data is $1.14 \mathrm{~m}$ (45.0 in.) from the nose.

\section{MASS PROPERTIES}

Center of gravity coordinates (x,y, and z), moments of inertia (Ixx, Iyy, and Izz), and products of inertia (Ixy, Iyz, and Izy) were supplied by LLNL, Reference 16, and are listed in Table 4. Based on the inertia values in Table 4 the principal axis is aligned with the $\mathrm{x}$ axis to within $0.05^{\circ}$. 


\section{BUOYANCY ANALYSIS}

The hydrazine fuel tank is $0.152 \mathrm{~m}$ (6.0 in.) in diameter with 2:1 ellipsoidal end caps. The cylindrical section length is $0.787 \mathrm{~m}$ (31 in.). The total volume in the tank is $0.0162 \mathrm{~m}^{3}\left(0.5727 \mathrm{ft}^{3}\right)$ and the resulting empty ASTRID- 1 density is $0.525 \mathrm{~g} / \mathrm{cc}$ ( 32.77 $\left.\mathrm{lb} / \mathrm{ft}^{3}\right)$. If the ASTRID-1 survives the water impact intact it will float. For the baseline trajectory the impact velocity is $145 \mathrm{~m} / \mathrm{s}(476 \mathrm{ft} / \mathrm{s})$. Two beacons are located on the vehicle, one in the forward avionics section and the second in the \#1 tail fin. The beacons have a range of 1 to $2 \mathrm{mi}$ with a 10 day lifetime. Recovery is to be attempted with a small craft after the mission.

\section{BASELINE TRAJECTORY}

Two computer codes are employed for the trajectory analysis: a three-degree-offreedom (3DOF) simulation, Reference 17, and a 6DOF simulation, Reference 18. The 6DOF code, Program to Optimize Simulated Trajectories (POST), was developed by Martin Marietta Corporation for NASA and has been validated in numerous test flights. The 3DOF code is a JHU/APL developed code that has been employed in numerous Ballistic Missile Defense Organization (BMDO) funded experiments. The 3DOF code was also validated by comparison to the 6DOF results for the ASTRID-1 baseline trajectory.

The results reported below have been generated for a rotating spherical earth model. The base-line trajectory is calculated for zero winds.

The 6DOF code is not capable of simulating a rail launch so that the initial conditions for the 6DOF analysis are the conditions at the end of the rail. The end of rail conditions were determined with the $3 \mathrm{DOF}$ code. For the $\gamma_{0}=80^{\circ}$ trajectory, the conditions at the end of the $18.29 \mathrm{~m}$ (60 foot) long rail are:

$\begin{array}{ll}\text { time,sec } & 1.67 \\ \text { velocity, } \mathrm{m} / \mathrm{s}(\mathrm{ft} / \mathrm{s}) & 22.0(72.1) \\ \text { altitude, } \mathrm{m}(\mathrm{ft}) & 20.0(65.7) \\ \text { weight, } \mathrm{kg}(\mathrm{lbs}) & 16.83(37.10)\end{array}$

The effects of rail friction were investigated employing a simple kinetic friction assumption where the frictional force is given as the product of the kinematic friction coefficient and the normal force between the rail and the launch shoes. Note that, to a first approximation, the frictional force is independent of contact area and velocity. The normal force is given by the weight times the cosine of the rail elevation angle. The kinematic friction coefficient is assumed as $\mu=0.1$ applicable for steel on steel. The frictional force is then given as,

$$
\mathrm{F}_{\mathrm{f}}=\mu^{*} \mathrm{~W}^{*} \cos \left(\gamma_{0}\right)=1.397 \mathrm{~N}(0.31 \mathrm{lbs}) \text {. }
$$


Subtracting $\mathrm{F}_{\mathrm{f}}$ from the sea level delivered thrust for the rail phase of the flight resulted in a $0.5 \%$ loss in end of rail velocity and a $0.5 \%$ increase in time on rail. The effects of rail friction have been neglected in the results reported here-in.

For the nominal (90 lb sea level thrust) trajectory, altitude, velocity, flight path angle, and range as a function of time, are tabulated in the Appendix. Shown in Figure 5 are the latitude, longitude, and altitude plot for the baseline trajectory. The altitude/ range profile is shown in Figure 6. Burnout occurs at $36.06 \mathrm{sec}$ at an altitude of $3.52 \mathrm{~km}$ $(11,542$ feet) with apogee at $38.83 \mathrm{sec}$ at a $3.56 \mathrm{~km}$ (11,670 foot) altitude. Total range is $9.664 \mathrm{~km}(5.22 \mathrm{~nm})$. The ground track of the baseline trajectory is shown in Figure 7 . The next 8 Figures show time histories of Mach number in Figure 8, dynamic pressure in Figure 9, spin rate and aerodynamic frequency in Figure $10^{1}$, angle of attack and yaw angle in Figure 11, flight path angle in Figure 12, range in Figure 13, altitude in Figure 14 and axial acceleration in Figure 15. Total time of flight is $75.53 \mathrm{sec}$.

The initial rail elevation (flight path angle, $\gamma_{0}$ ) has been selected as $\gamma_{0}=80^{\circ}$, and VAFB has requested that we investigate the possibility of lowering $\gamma_{0}$ from $80^{\circ}$ to $70^{\circ}$, Reference 7 . The higher $\gamma_{0}$ alleviates 'fuel starvation' problems whereas the lower $\gamma_{0}$ reduces impact dispersions due to winds. Shown in Figure 16 is the altitude-range profile of three trajectories with initial $\gamma_{0}$ of $70^{\circ}, 75^{\circ}$, and $80^{\circ}$. Note that, for the $\gamma_{0}=$ $80^{\circ}$ trajectory, burn out occurs slightly prior to apogee (approximately $2.77 \mathrm{sec}$ ), whereas for the lower $\gamma_{0}$ 's burn out occurs after apogee. The ASTRID-1 will be rotating at approximately $3.74 \mathrm{rev} / \mathrm{sec}(23.5 \mathrm{rad} / \mathrm{s})$ at burn-out, Figure 10. At apogee the total acceleration will be zero and the fuel remaining in the tank will be forced to the tank walls due to the centrifugal forces. Past apogee, the fuel will be forced to the forward region of the tank and the axial fuel port will be dry resulting in 'fuel starvation', with the possibility of vehicle impact with fuel remaining in the tank. The option of offloading propellant, which would allow a lower initial $\gamma_{0}$, would also result in a shorter propulsion system burn time and was not considered as it would compromise the flight test goal of evaluating the propulsion system performance.

\section{DISPERSIONS}

There are four general sources of error in predicting the impact location of the ASTRID-1 vehicle. These sources are - initialization, environmental, nominal mass/ propulsion /aerodynamic properties, and missile asymmetries. The initialization errors include such items as errors in elevation, azimuth, launch velocity, and errors that result from tip-off that may occur when the forward launch lug leaves the launch rail. Impact errors resulting from environmental factors include errors in wind, air temperature, and air density. The mass properties when on the launch rail may be different than the values being currently estimated and some of the propulsion and aerodynamic properties

1 Note that the two traces are sufficiently different that pitch-roll interactions will not be a problem. 
cannot be predicted accurately. The missile asymmetries include such items as center of gravity offset from the longitudinal axis, inclination of the principal axis, misalignment of the fore and aft sections of the body relative to the center-body section, tail misalignment, misalignment of the thrust axes, and variation in thrust magnitude.

The vehicle/launcher tolerances to be presented are not based on statistical data as the launch of the ASTRID-1 is a first of its kind. The tolerances are the result of considerations by LLNL personnel based on recent experiences in assembling the vehicle and launcher. The first set of error sources is in the initialization. For these we have identified the launcher elevation $80 \pm 1.0^{\circ}$ and azimuth $245 \pm 5^{\circ}$ settings as "conservative" estimates. For the initial ASTRID-1 weights it is estimated that the inert weight is $8200 \pm 100 \mathrm{~g}$ and the propellant load is $7600 \pm 50 \mathrm{~g}$. The nozzles, canted through the initial $\mathrm{cg}$ location, have been estimated to be set at $2.78 \pm 0.75^{\circ}$ and the fins set at $1.0 \pm 0.15^{\circ}$. The $\mathrm{cg}$ offset has been assumed as $0.0 \pm 0.1 \mathrm{~cm}$. The alignment of the three body sections, forward skirt, central fuel tank, and aft skirt is estimated as $0 \pm$ $0.15^{\circ}$. The dispersion resulting from a variation in flow rate is estimated to be $0.1163 \pm$ $0.00233 \mathrm{lbs} / \mathrm{sec}$ (i.e., $\pm 2 \%$ ) for each of the 4 nozzles. For the flow rate dispersions the vacuum propellant specific impulse was maintained at $225.5 \mathrm{sec}$ with the vacuum thrust being therefore proportional to the flow rate.

In order to make 6DOF simulation predictions of the worst case aerodynamic loads and the maximum dispersions in the flight path, it was necessary to account for uncertainties in the aerodynamic estimates calculated by the prediction codes, References 12 and 13.

The uncertainties arise from two sources. First, there are uncertainties in the geometry of the vehicle due to manufacturing and assembly tolerances. We assumed a tail and body misalignment of $0.15^{\circ}$. Second, the accuracy of the aerodynamic prediction codes as listed in Table 3.

The effects of vehicle geometry uncertainties were accounted for using the assumption that the error in alignment of each of the four tail fins could occur simultaneously (i.e., all four off by $0.15^{\circ}$ ) but that these errors will occur independently of the error in alignment of the afterbody. Error in alignment of the nose fairing was determined to have negligible effect on the aerodynamic coefficients and was not considered further. The combined effect of the tail and afterbody alignment errors was approximated as the root sum of the squares (RSS) of the effects of the two individual misalignments. These effects were accounted for in the $\mathrm{C}_{\mathrm{mo}}$ coefficient. Combining these factors, nominal $6 \mathrm{DOF}$ inputs were modified as follows: 
$\mathrm{C}_{\mathbf{A}}$

$\mathrm{C}_{\mathrm{N} \alpha}, \mathrm{C}_{\mathrm{Y} \beta}, \mathrm{C}_{\mathrm{m} \alpha}, \mathrm{C}_{\mathrm{n} \beta}$

$\mathrm{C}_{\mathrm{lo}}, \mathrm{C}_{\mathrm{mq}}$

$\mathrm{C}_{\mathrm{mo}}$ multiply by 1.1 to account for code accuracy. multiply by 1.2 to account for code accuracy. multiply by $1 / 1.2$ to account for code accuracy multiply by $1.2 \times 1.15$ to account for code accuracy and tail misalignment in roll deflection includes pitching moment coefficient resulting from the launch lugs (a very small effect) plus the RSS of the moment coefficients resulting from $0.15^{\circ}$ fin alignment and $0.15^{\circ}$ aft body misalignment.

The multipliers for $\mathrm{C}_{\mathrm{lp}}, \mathrm{C}_{\mathrm{mq}}$ and $\mathrm{C}_{\mathrm{nr}}$ (i.e., 1.2 or 0.8 ) were selected to result in maximum trim angle of attack resulting from roll-pitch coupling effects. For the maximum load condition, a gust velocity of $8.99 \mathrm{~m} / \mathrm{s}(29.5 \mathrm{ft} / \mathrm{s})$ normal to the body centerline was superimposed on the trim angle of attack. Without the gust the trim angle of attack is $0.45^{\circ}$. With the gust, the angle of attack is $2.26^{\circ}$. For the maximum dispersion condition, no gust velocity was imposed.

In addition, the nozzles were all deflected $\pm 0.75^{\circ}$ in pitch and yaw.

The major source of dispersion is the winds. For the wind dispersions, the mean November wind at VAFB shown in Figure 17, taken from Reference 4, has been employed. The wind speed profile shown in Figure 17 was applied at wind azimuths of $0^{\circ}, \pm 30^{\circ}, \pm 60^{\circ}, \pm 90^{\circ}, \pm 105^{\circ}, \pm 120^{\circ}, \pm 135^{\circ}, \pm 150^{\circ}, \pm 165^{\circ}$, and $\pm 180^{\circ}$ with respect to the launch azimuth of $245^{\circ}$.

'The impact points resulting from the above dispersion sources are shown in Figure 18. The aerodynamic uncertainties, fin misalignment, body misalignment, and nozzle misalignment have been combined, as described above, to represent a worst-case combination. The inert weight, propellant weight, flow rate, rail elevation and azimuth heading dispersions were individually evaluated with the 6DOF code. The dispersions can be grouped into three categories. The first category consists of the flight path angle, inert weight, propellant weight, and propellant flow rate. They are closely grouped about the nominal impact point. This group results mainly in down-range dispersions of the order of $0.135 \mathrm{~km}$ (446 ft). The second category consists of the launch azimuth and aerodynamic/nozzle dispersions with a RSS cross-range dispersion of $\pm 1.30 \mathrm{~km}( \pm 4256$ $\mathrm{ft}$ ). The third and most significant category is the dispersions due to the winds.

If we limit the wind azimuth to within $\pm 90^{\circ}$ of the headwind azimuth, the combined dispersion footprint is shown in Figure 19. Because of the non-linear response of the spinning vehicle to some of the error sources (e.g., winds and aerodynamic uncertainties), standard techniques for combining the individual error sources were not employed. The up-range, down-range, and cross-range impact dispersions about the nominal impact point were found by the RSS of the aerodynamic/nozzle, propellant flow rate, inert weight, propellant weight, initial rail elevation angle and initial rail azimuth angle dispersions. The final values are $0.11 \mathrm{~km}(0.057 \mathrm{~nm}), 0.96 \mathrm{~km}(0.517 \mathrm{~nm})$, and $1.30 \mathrm{~km}(0.70 \mathrm{~nm})$ in up-range, down-range and cross-range dispersions, from the 
nominal impact point, respectively. A circular dispersion of $1.13 \mathrm{~km}(0.7 \mathrm{~nm})$ was applied to the mean November VAFB wind dispersions to arrive at the 'albatross' shape shown in Figure 19.

\section{BALLISTIC WIND WEIGHTING FACTORS}

The ballistic wind is the wind having constant speed and azimuth that has the same impact error as that of the real wind. The method is shown in Table 5. Nine altitude bands were selected to evaluate the ballistic wind weighting factors, and six wind speeds were selected to evaluate the range partials required for impact predictions. Note that $90 \%$ of the dispersion results from the winds at altitudes from 0 to $0.305 \mathrm{~km}(1000$ feet).

The methodology was applied to the wind dispersion results discussed above and the comparison is shown in Figure 20. Note that the method yields reasonably accurate impact dispersions. The method will be employed at the launch site to evaluate potential dispersions due to measured winds.

The large crossrange dispersions due to wind conditions are due mainly to the high launcher elevation angle, $\gamma_{0}$. The initial change in ground track azimuth at the endof-rail is given approximately by,

$$
\Delta \mathrm{AZ}=\operatorname{trn}^{-1}\left[\mathrm{~V}_{\mathrm{W}} /\left(\mathrm{V}_{0} \cos \left(\gamma_{0}\right)\right]\right.
$$

For a 5 knot cross wind with $\mathrm{V}_{0}=22.0 \mathrm{~m} / \mathrm{s}(72.1 \mathrm{ft} / \mathrm{s})$ and $\gamma_{0}=80^{\circ}, \Delta \mathrm{AZ}=34.0^{\circ}$. The large stability margin ${ }^{2}$ of the vehicle ( 24 in. at launch) results in the vehicle weathercocking rapidly into the wind.

\section{STRUCTURAL ANALYSIS}

A static and normal modes analysis was performed on the ASTRID 1 vehicle, in order to verify the structural integrity of the vehicle and to characterize its dynamic behavior. A NASTRAN finite element model containing over 10000 degrees of freedom was developed in order to accurately represent the vehicle structure. A wire-frame representation of the model is shown in Figure 21. The ASTRID 1 vehicle's forward and aft skirt, pressure tank, thrust plate weldment, radome, and fins were modeled as plate elements. The thru tubes in the pressure vessel were not modeled, as they were not a part of the base-line design. The materials and dimensions for these parts were determined using the detailed drawings provided to JHU/APL by LLNL. Homogeneous material properties were assumed. The composite Kevlar/Epoxy fins were modeled using

2 An analysis was conducted to investigate reducing the tail size to shift the center of pressure or employing ballast to shift the $\mathrm{cg}$, both in a direction to reduce the stability margin. Neither option appeared promising with regard to reducing wind dispersions. 
the data provided in Reference 19. There was not enough technical details on the composite layups or test data to provide an independent check as to the strength of the fins. Properties for the radome were used for the same reasons as for the fins.

The propulsion system avionics, thrusters, and nose plug were modeled with concentrated masses. The magnitudes were obtained from the data provided in Reference 16.

The two critical structural joints on the vehicle (i.e., between the pressure tank and the forward and aft skirt) were modeled using plate elements to represent the flanges and rig:d elements to represent the bolts in order to recover forces and stresses in these elements.

The liquid hydrazine in the pressure tank was modeled using non-structural masses that were tied via rigid elements to the tank wall. The magnitude and inertia properties of these discrete masses varied linearly along the length of the tank. No free surface effects or fluid-structure interactions were modeled. The sum total of the fuel mass and the cg were made to agree with that of Reference 16, for the flight time in which the worst-case loading occurred.

The worst-case flight conditions were found to occur approximately 21 seconds into the flight. The weight of the vehicle at that time was estimated at $15.1 \mathrm{~kg}(33.2 \mathrm{lbs})$ with a center of gravity of $1.064 \mathrm{~m}$ (41.9 in.) from the nose. The finite element model was maintained to within 3 percent of these values. The aerodynamic loads corresponding to this flight condition are listed in Table 6, along with a second set of flight loads which includes the effect of a $8.99 \mathrm{~m} / \mathrm{s}(29.5 \mathrm{ft} / \mathrm{s})$ gust load. In addition to the aerodynamic and inertia loads, a thrust load of 131 pounds was applied to the aft end of the vehicle, the fuel tank was pressurized to 100.0 pounds per square inch, and the entire vehicle was subjected to a roll rate of $6.15 \mathrm{rev} / \mathrm{sec}$.

The ASTRID 1 vehicle was designed to have a minimum factor of safety of 1.25 on ultimate, 1.10 on yield, and 1.25 on buckling. Stress contour plots of the vehicle are given in Figures 22 through 24. Figure 22 shows the von Mises stress on the surface of the vehicle for loading case without wind gusts. The high stresses occur in the wall of the pressurized fuel tank. The main contribution being the 100 psi internal tank pressure. Figure 23 shows the stresses on the vehicle surface for the load case with the specified wind gusts. The high stresses again occur in the wall of the fuel tank and also at the tank/aft skirt joint. A more detailed description of the stresses in the region are shown in Figure 24 with a maximum von Mises stress of $45 \mathrm{ksi}$. Table 7 summarizes the margins of safety for the major structural elements of the vehicle.

The static load test, described in Reference 21, was duplicated using the finite element model to validate the model and to provide a bench mark for the current vehicle design. For the $9.06 \mathrm{~kg}(20 \mathrm{lb})$ static load case, the measured deflection at the aft end of the vehicle, was $0.495 \mathrm{~cm}(0.195 \mathrm{in}$.) as compared to the finite element model with a deflection of $0.533 \mathrm{~cm}(0.210 \mathrm{in}$. $)$. 
The effects of the 100 psi internal tank pressure on the stiffness of the structure was found to be negligible. This was determined by comparing static load test data with the model. The deflection difference was negligible between a vehicle with a pressurized tank and one with no pressure in the tank.

Based on NASTRAN normal modes analysis, the primary resonant frequency (first mode bending) for the ASTRID 1 vehicle was determined to be $48.6 \mathrm{~Hz}$ - without the effect of the pressurized tank and is illustrated in Figure 25. This resonant frequency is comparable to the frequency calculated in Reference 20 when one considers the differences in the two models. The model in Reference 20 did not consider any structure forward of the tank and had assumed a vehicle weight of $11.16 \mathrm{~kg}$ ( $24.6 \mathrm{lbs})$. In addition the aft skirt was $0.33 \mathrm{~m}$ (13.0 in.) shorter than the current design.

Since the primary resonant frequency of the vehicle is far enough removed from the aerodynamic frequency of approximately $10 \mathrm{~Hz}$, no significant interaction is expected. Figure 26 shows that the primary resonant frequency of the fins (first bending mode) is $82 \mathrm{~Hz}$. This is comparable with the results presented in Reference 19, when one takes into account the increased mass of the fin and the boundary conditions imposed by the vehicle.

\section{CONCLUSIONS}

The structural, aerodynamic, and trajectory analysis of the ASTRID-1 vehicle has been completed. The dynamic behavior of the spinning propellant has not been considered. The two tubes that pierce the fuel tank head caps, to carry cables from the aft section to the forward section, has not been included in the structural analysis. The major conclusions are:

1) The vehicle is very stable throughout flight (stability margin $=17$ to 24 inches).

2) The aerodynamic frequency and the roll rate are such that pitch-roll interactions will be small.

3) The high stability margin combined with the high launcher elevation angle makes the vehicle flight path highly sensitive to perturbations during the initial phase of flight, i.e., during the first second of flight after leaving the rail.

4) The major impact dispersions for the test flight are due to winds. The wind impact dispersions are $90 \%$ dictated by the low altitude, 0 to $1000 \mathrm{ft}$., wind conditions.

5) In order to minimize wind dispersions, head wind conditions are favored fur the launch as November VAFB mean tail winds result in land impacts. The ballistic wind methodology can be employed to assess the impact points of winds at the launch site. 
Appliced Phisics Laboralomy

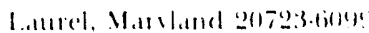

Attachment 1

AL-94-S020

Page 12

6) The stress analysis indicates that the vehicle is designed with sufficient strength to endure the proposed flight.

7) Structural and aerodynamic frequencies are separated sufficiently to preclude resonance phenomena.

A number of JHU/APL memorandum have been recently published (References 22 to 26) documenting the aerodynamic analysis conducted for the ASTRID-1 vehicle that were not referenced above.

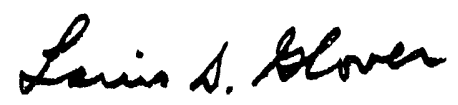

L. S. Glover

a. O. Swaskiw

A. P. Iwaskiw

hland Qiciunten

M. A. Oursler

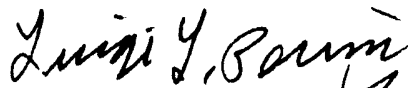

L. L. Perini

E. D. Schaefer

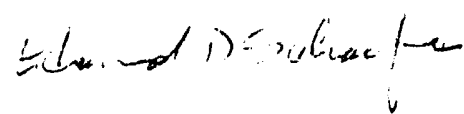




\section{REFERENCES}

1) "Range Safety Requirements," Western Space and Missile Center, WSMCR 127-1, December 15, 1989.

2) Whitehead, John C., "Demand Thrust Pumped Propulsion With Automatic Warm Gas Valving," AIAA paper 92-3539, Presented at AIAA/SAE/ASEE 28th Joint Propulsion Conference and Exhibit, July 6-8, 1992.

3) Downey, R. M., "Explosives Safety Standards," Department of the Air Force, Headquarters US Air Force, Wash. DC, AF Regulation 127-100, August 3, 1990.

4) "Vandenberg Air Fore Base, California, Range Reference Atmosphere, 0-70 km Altitude," Document 362-83, Range Reference Atmosphere committee, Meteorology Group, Range Commanders Council, April 1983.

5) Bertolini, Lou, Fax to Luigi Perini, JHU/APL, "ASTRID Launch Tower," October 6, 1993.

6) Fax from Michael Richardson, $30 \mathrm{SPW} / \mathrm{SEY}$, to Luigi Perini, JHU/APL, "Information for ASTRID Trajectory Analysis," July 22, 1993.

7) Fax from Ron Cortopassy, $30 \mathrm{SPW} / \mathrm{SEY}$, to $30 \mathrm{RANS} / \mathrm{DOR}$, "Launcher Position Requirement for ASTRID," August 3, 1993.

8) Bertolini, Lou, Fax to Luigi Perini, JHU/APL regarding change of launch azimuth, October 6, 1993.

9) Telecon from John Whitehead, LLNL, to Luigi Perini, JHU/APL, July 22, 1993.

10) Telecon from Lee Pittenger, LLNL, to Luigi Perini, JHU/APL, September 1993.

11) Sykes, D. M., "Cylindrical and Boat-Tailed Afterbodies in Transonic Flow with Gas Ejection," AIAA Journal, Vol. 8, No. 3.

12) Burns, K. A., Deters, K. J., Stoy, S. L., Vukelich, S. R., and Blake, W. B., " MISSILE DATCOM," Wright Patterson Air Force Base, OH, Report WL-TR-93-3043, June 1993.

13) Devan, L. and Mason, L., "Aerodynamics of Tactical Weapons to Mach Number 8 and Angle of Attack $180^{\circ}$ : Part II, Computer Program and Users Guide," NSWC TR 81-358, Sep 81, NSWC, Dahlgren, VA. 
14) Vukelich, S. R., Stoy, S. L., Burns, K. A., Castillo, J. A., and Moore, M. E., "Missile DATCOM Volume I-Final Report," AF WALTR-86-3091, December 1988, Air Force Wright Aeronautical Laboratory, Wright Patterson AFB, OH.

15) Mason, L., Devan, L., Moore, F. G., and McMillan, D., "Aerodynamic Design Manual For Tactical Weapons," Naval Surface Weapons Center, Dahlgren, Virginia, Report NSWC TR 81-156, July 1981.

16) L. Pittenger, "Mass Properties," Lawrence Livermore National Laboratory memorandum, August 25, 1993.

17) Perini, L. L., "Users Manual for the 3DOF Trajectory Computer Program," ANSP-M-6, JHU/APL, September, 1973.

18) Brauer, G. L., Cornick, D. E., Olson, D. W., Petersen, F. M., and Stevenson, R., "Six-Degree-of-Freedom Program to Optimize Simulated Trajectories (6D POST)," Martin Marietta Corporation Report numbers Vol. 1-MCR-87-583, Vol. 2-MCR-87-584, and Vol. 3-MCR-87-585, September 1990. NASA contract NAS1-18147 under the direction of Mr. Richard W. Powell, NASA Langley Research Center.

19) "Kevlar Fins Calculated Natural Frequencies," Telecopy Transmittal Report, from Al Harral to Lee Pittenger of LLNL; May 4, 1993

20) "Primary Probe Model and Structural Analysis," Telecopy Transmittal Repcrt, from Al Harral to Lee Pittenger of LLNL, Feb 3, 1993

21) "Flexure Test Prototype Rocket Frame," Fax from Lee Pittenger, LLNL, to Ed Schaefer, JHU/APL, October 2, 1993.

22) Glover, L. S., "A Ballistic Wind Procedure for Estimating the Effects of Wind on Impact Dispersion and on Time of Apogee for ASTRID Flight 'Tests", JHU/APL memorandum, November 27, 1993.

23) Glover, L. S., "Summary of Aerodynamic Effort on ASTRID", JHU/APL memorandum, January 5, 1994.

24) Oursler, M. A., "ASTRID Aerodynamic Model Development", JHU/APL memorandum SSD/PM-94-0005, January 18, 1994.

25) Oursler, M. A., "Anomalies Noted in MISSLE DATCOM, Rev 4/91, During ASTRID 1 Modeling", JHU/APL memorandum SSD/PM-94-0006, January 18, 1994.

26) Oursler, M. A., "Determination of Aerodynamic Loads for ASTRID 1", JHU/APL memorandum SSD/PM-94-0007, January 18, 1994. 
Table 1. Vandenberg AFB November Reference Atmosphere

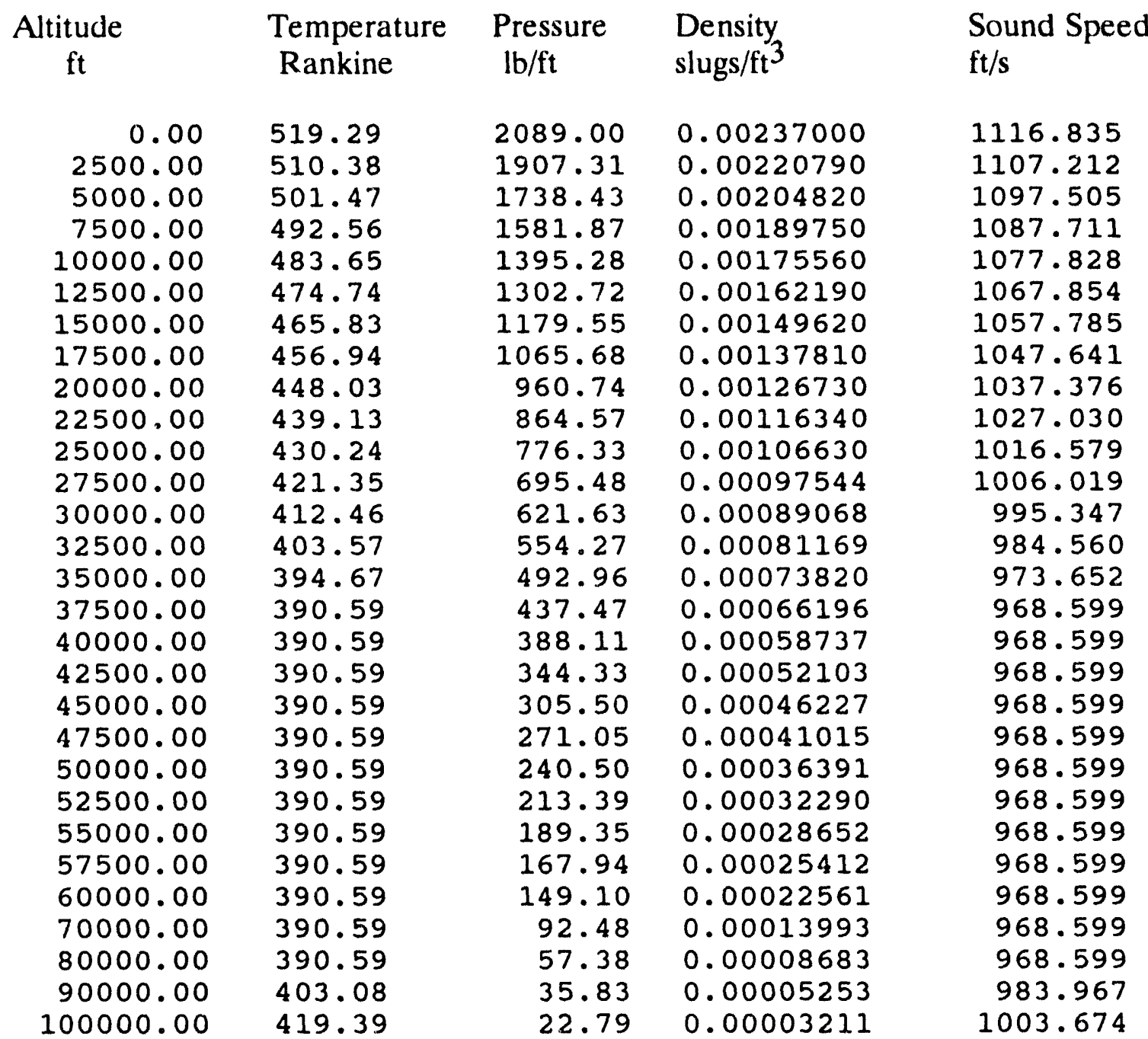


'Table 2. ASTRID-1 Propulsion Parameters.

A set of propulsion parameters was received from John Whitehead, LLNL, Reference 9 and Reference 10. The final propulsion parameters, per nozzle, employed in the analysis are based on a January 7, 1994 telephone conversation with Lee Pittinger, LLNL, that recommended a sea level thrust of $88.76 \mathrm{~N}(20.0 \mathrm{lbs})$ :

w,Propellant flow rate

$0.1164 \mathrm{lbs} / \mathrm{s}$

$\mathrm{P}_{\mathrm{C}}$,Chamber pressure 458 psia

$\mathrm{P}_{\mathrm{e}}$,Nozzle exit pressure 7.33 psia

$\widehat{C}_{\mathrm{T}}$,Thrust coefficient, sea level 1.398

$\mathrm{T}_{\mathrm{SL}}$, Sea level delivered thrust $20.00 \mathrm{lbs}$ $T_{V}$,Vacuum delivered thrust $26.24 \mathrm{lbs}$ $I_{\text {sp,SL, Sea level propellant specific impulse }}$ $I_{\mathrm{Sp}, \mathrm{V}}$, Vacuum propellant specific impulse $\epsilon \stackrel{=}{=} A_{e} / A^{*}$, Nozzle expansion ratio $D^{*}$, Nozzle throat diameter

From the above parameters the characteristic velocity, $\mathrm{C}^{*}$, can be computed, $\mathrm{C}^{*}=\mathrm{g}^{*} \mathrm{P} \mathrm{C}^{*} \mathrm{~A}^{*} / \mathrm{w}=4770 \mathrm{ft} / \mathrm{sec}$,

and the throat area for each nozzles is

$$
\mathrm{A}^{*}=\pi^{*} \mathrm{D}^{* 2} / 4=0.05309 \mathrm{in}^{2}
$$

with an exit area,

$$
A_{e}=8^{*} A^{*}=0.4247 \text { in }^{2} \text {. }
$$

The effective nozzle diameter, for 4 nozzles, is given by,

$$
D_{\mathrm{e}}=\operatorname{Sqrt}\left(4^{*} 4^{*} \mathrm{~A}_{\mathrm{e}} / \pi\right)=1.47^{\prime \prime} \text {. }
$$

Based on Mach function tables(ratio of specific heats, $\gamma=1.3$ ) the exit Mach number is $\mathrm{M}_{\mathrm{e}}=3.68$ for a nozzle area ratio, $\epsilon=8$. 
Table 3. ASTRID-1 Aerodynamic Coefficients and Derivatives.

$\begin{array}{lcccccccc}\text { Mach } & c_{\mathrm{A}} & \mathrm{C}_{\mathrm{N} \alpha} & \mathrm{C}_{\mathrm{Y} \beta} & \mathrm{C}_{\mathrm{m} \alpha} & \mathrm{C}_{\mathrm{n} \beta} & \mathrm{C}_{\mathrm{l} \delta} & \mathrm{C}_{\mathrm{lp}} & \mathrm{C}_{\mathrm{mo}} \\ 0.00 & 0.331 & 0.384 & -0.384 & -0.938 & 0.938 & 0.249 & -39.3 & 0.00507 \\ 0.50 & 0.331 & 0.384 & -0.384 & -0.938 & 0.938 & 0.249 & -39.3 & 0.00507 \\ 0.80 & 0.346 & 0.428 & -0.428 & -1.085 & 1.085 & 0.285 & -41.6 & 0.00942 \\ 0.90 & 0.534 & 0.454 & -0.454 & -1.164 & 1.164 & 0.303 & -45.1 & 0.01198 \\ 1.00 & 1.140 & 0.503 & -0.503 & -1.264 & 1.264 & 0.334 & -48.1 & 0.01318 \\ 1.05 & 1.240 & 0.587 & -0.587 & -1.644 & 1.644 & 0.395 & -49.8 & 0.01312 \\ 1.20 & 0.947 & 0.535 & -0.535 & -1.473 & 1.473 & 0.353 & -57.1 & 0.01282 \\ 1.50 & 0.791 & 0.330 & -0.330 & -0.619 & 0.619 & 0.231 & -48.8 & 0.01163 \\ 1.75 & 0.717 & 0.275 & -0.275 & -0.424 & 0.424 & 0.190 & -41.3 & 0.01097 \\ 2.00 & 0.655 & 0.240 & -0.240 & -0.291 & 0.291 & 0.161 & -35.8 & 0.01061 \\ 3.00 & 0.520 & 0.172 & -0.172 & -0.093 & 0.093 & 0.102 & -23.5 & 0.01013\end{array}$

\begin{tabular}{llrlr} 
Mach & \multicolumn{3}{c}{$C_{\mathrm{mq}}$} & \multicolumn{2}{c}{$\mathrm{C}_{\mathrm{nr}}$} \\
& $\mathrm{cg}=35 "$ & $\mathrm{cg}=47 "$ & $\mathrm{cg}=35 "$ & $\mathrm{cg}=47 "$ \\
0.00 & -1110. & -456. & -1110. & -456. \\
0.50 & -1110. & -456. & -1110. & -456. \\
0.80 & -1246. & -513. & -1246. & -513. \\
0.90 & -1404. & -590. & -1404. & -590. \\
1.00 & -1228. & -480. & -1228. & -480. \\
1.05 & -1123. & -417. & -1123. & -417. \\
1.20 & -1213. & -441. & -1213. & -441. \\
1.50 & -1038. & -456. & -1038. & -456. \\
1.75 & -911. & -420. & -911. & -420. \\
2.00 & -826. & -395. & -826. & -395. \\
3.00 & -632. & -326. & -632. & -326.
\end{tabular}

$c_{A}$, ca axial force coefficient, power on and off.

$\mathrm{C}_{\mathrm{N} \alpha}$, cna normal force derivative, $\mathrm{deq}^{-1}$

CY $\beta$, cyb side force derivative, $\mathrm{deg}^{-1}$,

$\mathrm{C}_{\mathrm{m} \alpha}$, cma pitching moment derivative, $\mathrm{deg}^{-1}$

$\mathrm{C}_{\mathrm{n} \beta}$, cwb yawing moment derivative, $\mathrm{deg}^{-1}$

$c_{l} \delta$, rolling moment derivative, $\mathrm{deg}^{-1}$

$C_{l p}$, cllp rolling moment derivative due to roll rate, per rad

$\mathrm{C}_{\mathrm{mo}}$, cmo pitching moment coefficient due to asymmetric launch lugs

$\mathrm{c}_{\mathrm{mq}}$, cmq pitching moment derivative due to pitch rate, per rad

$\mathrm{C}_{\mathrm{nr}}$, cwr yawing moment derivative due to yaw rate, per rad

Item

$\mathrm{C}_{\mathrm{A}}$

$\mathrm{C}_{\mathrm{N} \alpha}$

$\mathrm{CY} \beta$

$\mathrm{C}_{\mathrm{m} \alpha}$

$\mathrm{C}_{\mathrm{n} \beta}$

$\mathrm{C}_{\mathrm{I} \delta}$

$\mathrm{C}_{\mathrm{lp}}$

$\mathrm{C}_{\mathrm{mo}}$

$\mathrm{C}_{\mathrm{mq}}$

$\mathrm{C}_{\mathrm{nr}}$

\section{Accuracy}

$\pm 10 \%$

$\pm 20 \%$

$\pm 20 \%$

$\pm 20 \%$

$\pm 20 \%$

$\pm 20 \%$

$\pm 20 \%$

$\pm 20 \%$

$\pm 20 \%$

$\pm 20 \%$ 

inertia as a function of weight.

\begin{tabular}{|c|c|c|c|c|c|c|c|c|c|}
\hline & \multicolumn{2}{|c|}{ Uetric Units: } & & \multicolumn{5}{|c|}{ Moments of Inertia $\mathrm{kg} / \mathrm{m}^{2} \ldots \ldots \ldots \ldots$} & \multirow[b]{2}{*}{ Izy } \\
\hline & $x, m(l)$ & $y, m$ & $2, m$ & $D x$ & lyy & 122 & by & lyz & \\
\hline 7.9984 & -1.0497 & $0.000) 36$ & 0.00071 & 0.05412 & 3.104 & 3.110 & -0.00113 & -0.00039 & -0.00212 \\
\hline 2.9984 & - 0.9310 & 0.00012 & 0.00025 & 0.09767 & 4.125 & 4.131 & .0 .00079 & -0.00039 & -0.00145 \\
\hline 1.9984 & -0.9511 & 0.00013 & 0.00026 & 0.09477 & 3.918 & 3.92 & -0.00085 & 039 & .0 .00 \\
\hline 0.9984 & .0 .9706 & 0.00014 & 0.00027 & 0.09187 & 3. 742 & 3.748 & -0.00091 & -0.00039 & -0.00 \\
\hline 19.9984 & -0.9893 & 0.00014 & 0.00028 & 0.08896 & 3.593 & 3.600 & $-0.000 \% 6$ & $\cdot 0.00039$ & -0.00178 \\
\hline 8.9984 & -1.0071 & 0.00015 & 0.00030 & 0.08606 & 3.471 & 3.478 & -0.00101 & -0.00039 & -0.00188 \\
\hline 17.9984 & -1.0238 & 0.00016 & 0.00032 & 0.08316 & 3.373 & 3.380 & -0.00106 & -0.00039 & -0.00197 \\
\hline 16.9984 & -1.0394 & 0.00017 & 0.00033 & 0.08025 & 3.297 & 3.304 & -0.00110 & -0.00039 & -0.00206 \\
\hline 15.9984 & -1.0535 & 0.00918 & 0.00035 & 0.07735 & 3.242 & 3.248 & -0.00115 & .0 .00039 & -0.00214 \\
\hline 14.9984 & -1.0659 & 0.00019 & 0.000138 & 0.07445 & 3.203 & 3.210 & -0.00118 & -0.00039 & -0.10221 \\
\hline 13.9984 & -1.0762 & 0.00021 & 0.00041 & 0.07145 & 3.179 & 3.186 & -0.00121 & .0 .00039 & -0.00227 \\
\hline 12.9984 & -1.0839 & 0.00022 & 0.00044 & 0.06864 & 3.167 & 3.173 & -0.00123 & -0.00039 & -0.00232 \\
\hline 11.9984 & -1.0884 & 0.00024 & 0.000047 & 0.06573 & 3.162 & 3.168 & -0.00125 & -0.00039 & -0.00234 \\
\hline 10.9984 & -1.08 & 0.000 & 0.00052 & 5283 & 3.160 & 3.167 & -0.00125 & -0.00039 & -0.00234 \\
\hline & -1.08 & & & & 3.150 & 3.162 & -0.00123 & -0.00039 & .0 .00231 \\
\hline 8.9984 & -1.0716 & 0.00032 & 0.00063 & 0.05702 & 3.141 & 3.147 & -0.00120 & -0.00039 & -0.00225 \\
\hline
\end{tabular}

\section{English Units:}

\begin{tabular}{|c|c|c|c|c|c|c|c|c|}
\hline \multirow[b]{2}{*}{$\mathrm{m}, \mathrm{lb}$} & & \multicolumn{4}{|c|}{ Moments of Inertia,slugs $-\mathrm{ft}^{2} \ldots \ldots \ldots$} & \multirow[b]{2}{*}{ lzy } \\
\hline & $\mathrm{x}, \mathrm{ft}(2)$ & $\mathrm{y}, \mathrm{ft}$ & $z, \mathrm{ft}$ & Lxo & lyy & $\mathrm{lzz}$ & lxy lyz & \\
\hline 50.71147 & -0.6956 & 0.000394 & 0.00082 & 0.072048 & 3.042895 & 3.047321 & $-0.00058-0.00029$ & -0.00107 \\
\hline 48.50647 & -0.6296 & 0.000427 & 0.000853 & 0.069909 & 2.890197 & 2.895361 & $-0.00063-0.00029$ & -0.00115 \\
\hline 46.30147 & -0.5657 & 0.000459 & 0.000886 & 0.067770 & 2.760367 & 2.764793 & $.0 .00067-0.00029$ & -0.00123 \\
\hline 44.09647 & -0.5043 & 0.000459 & 0.000919 & 0.065623 & 2.650454 & 2655618 & $-0.00071 \quad-0.00029$ & -0.00131 \\
\hline 41.89147 & -0.4451 & 0.000492 & 0.000984 & 0.063484 & 2.560458 & 2.565622 & $\begin{array}{lll}-0.00075 & -0.00029\end{array}$ & -0.00139 \\
\hline 39.68647 & -0.3911 & 0.000525 & 0.001050 & 0.061345 & 2.488166 & 2.493330 & $-0.00078-0.00029$ & -0.00146 \\
\hline 37.48147 & -0.3399 & 0.000558 & 0.001083 & 0.059198 & 2.432103 & 2.437267 & $\begin{array}{lll}-0.00081 & -0.00029\end{array}$ & -0.00152 \\
\hline 35.27647 & -0.2937 & 0.000591 & 0.001148 & 0.057059 & 2.391531 & 2.395957 & $-0.00084-1$ & .0 .00158 \\
\hline 33.07147 & -0.2530 & 0.000623 & 0.001247 & 0.054920 & 2.362762 & 2.367926 & $-0.00087-0.0$ & -0.00163 \\
\hline 30.86647 & -0.2192 & 0.000689 & 0.001345 & 0.052707 & 2.345058 & 2.350222 & $-0.00089-0.00029$ & -0.00168 \\
\hline 28.66147 & -0.1939 & 0.000722 & 0.001444 & 0.050634 & 2.336206 & $2.34 \sqrt{ } 632$ & $-0.00091 \quad-0.00029$ & -0.00171 \\
\hline 26.45647 & -0.1792 & 0.000787 & 0.001542 & 0.048487 & 2.332518 & 2.336944 & $-0.00092-0.00029$ & -0.00173 \\
\hline 24.25147 & -0.1782 & 0.000525 & 0.001706 & 0.046348 & 2.331042 & 2.336206 & $-0.00092-0.00029$ & -0.00173 \\
\hline 22.04647 & -0.1946 & 0.000951 & 0.001870 & 0.044209 & 2.328091 & 2.332518 & $-0.00091-0.00029$ & -0.00171 \\
\hline 19.84147 & -0.2343 & 0.001050 & 0.002067 & 0.042062 & 2.317026 & 2.321452 & $-0.00088-0.00029$ & -0.00166 \\
\hline 17.63647 & -0.3061 & 0.001181 & 0.002329 & 0.039923 & 2.289733 & 2.294159 & $-0.00084-0.00029$ & -0.00156 \\
\hline
\end{tabular}

Notes: (1) $X_{\mathrm{cg}}$ measured from nose, LLNL coordinate system, $x$ positive from nose forward

(2) Xcg measured from Xref $=45$ " from the nose, 6 DOF coordinate system, $x$ positive rearward. 
Table 5. Ballistic Wind Weighting Factors and Ballistic Wind Range Partials

Altitude Range, ft
0 to
300
300 to
600 to 1,000
1,000 to 2,000
2,000 to 5,000
5,000 to 10,000
10,000 to 15,000
15,000 to 20,000
20,000 to 30,000

Mid-Altitude, ft
150
450
800
1,500
3,500
7,500
12,500
17,500
25,000

Weighting Factor $(W)$
0.6605
0.1706
0.0747
0.0596
0.0365
0.0060
-0.0080
0.0000
0.0000

\begin{tabular}{rccccccc}
\multicolumn{7}{c}{ D, Down Range Matrix, nm } \\
$\psi /$ Vw & 0 & 3 & 6 & 9 & 12 & 15 & 20 \\
0.00 & 0.000 & -0.0960 & -0.2870 & -0.5600 & -0.9280 & -1.3840 & -2.1040 \\
30.00 & 0.000 & -0.1000 & -0.3010 & -0.5780 & -0.9330 & -1.3700 & -2.1090 \\
60.00 & 0.000 & -0.1080 & -0.3490 & -0.6630 & -1.0240 & -1.4270 & -2.1740 \\
80.00 & 0.000 & -0.1130 & -0.3970 & -0.7800 & -1.2040 & -1.6390 & -2.3680 \\
90.00 & 0.000 & -0.1140 & -0.4230 & -0.8560 & -1.3400 & -1.8250 & -2.5870 \\
110.00 & 0.000 & -0.1080 & -0.4660 & -1.0300 & -1.7010 & -2.3770 & -3.3600 \\
120.00 & 0.000 & -0.1010 & -0.4750 & -1.1160 & -1.9210 & -2.7490 & -3.9310 \\
135.00 & 0.000 & -0.0860 & -0.4680 & -1.2190 & -2.2790 & -3.4360 & -5.0480 \\
150.00 & 0.000 & -0.0700 & -0.4340 & -1.2670 & -2.6350 & -4.2770 & -7.2150 \\
165.00 & 0.000 & -0.0560 & -0.3920 & -1.2480 & -2.9010 & -5.1860 & -7.7150 \\
180.00 & 0.000 & -0.0510 & -0.3730 & -1.2220 & -2.9850 & -5.6820 & -8.9670
\end{tabular}

\begin{tabular}{|c|c|c|c|c|c|c|c|}
\hline$\psi /$ VW & 0 & 3 & 6 & 9 & 12 & 15 & 0 \\
\hline 0.0 & 0.000 & 0.0000 & 0.0000 & 0.0000 & 0.0 & 0.0 & 0000 \\
\hline 30 . & & & & 0 . & & 1. & \\
\hline & & & & 1. & & & \\
\hline 80 & & & & 2 . & & & \\
\hline 90 & & & 510 & 2 . & 3.17 & 3.4 & 860 \\
\hline 10 & & 1.0 & 2.1250 & 3.0580 & 3.75 & 4.2 & 4690 \\
\hline 0 & & 1.0100 & 2.1150 & 3.1510 & 3.96 & 4. & .8020 \\
\hline & 0 . & 0.8690 & 1.9390 & 3.0810 & 4.06 & 4.7 & 60 \\
\hline & & 0. & 220 & 2.6130 & 3.60 & & 60 \\
\hline & & & 490 & 1.5710 & & & 150 \\
\hline & 0.000 & .0000 & 0.0000 & 0.0000 & 0.0000 & 0.0000 & 0000 \\
\hline
\end{tabular}


Table 5 (Cont'd) Ballistic Wind Weighting Factors and Ballistic Wind Range Partials
$V W=$
Measured wind speed at the mid-altitude values listed above, $\mathrm{ft} / \mathrm{sec}$
$\mathrm{AZW}=$ Measured wind azimuth at the mid-altitude values listed above, deg
$\mathrm{W}=$ Weighting factor listed above
$\mathrm{CRD}=$
Cross range dispersion, positive right of nominal track.
$\mathrm{DRD}=$
Down-range dispersion, positive greater than no-wind range.
$\mathrm{BCW}=\sum \mathrm{VW} \mathrm{W}^{*} \mathrm{~W}^{*} \sin (\mathrm{AZW}-245), \mathrm{ft} / \mathrm{s}$
$\mathrm{CRD}=\mathrm{C}(\mathrm{BW}, \psi), \mathrm{nm}$
$B H W=\sum W^{*} W^{*} \cos (A Z W-245), f t / s$
$\mathrm{BW}=\operatorname{Sqrt}\left(\mathrm{BCW}^{2}+\mathrm{BHW}^{2}\right)$
$\psi=\sin ^{-1}(\mathrm{BCW} / \mathrm{BW})$
$\mathrm{DRD}=\mathrm{D}(\mathrm{BW}, \psi), \mathrm{nm}$ 
Table 6. Aerodynamic Loads at Time of Flight $=21.0$ Sec.

Aerodynamic Parameter

Fwd Body, Normal Force

Fwd Body, Axial Force

Aft Body, Normal Force Fin, Normal Force ( 2 Fins)

Fin, Axial Force ( 4 Fins)

Angle of Attack (deg)

$$
\begin{aligned}
& \text { Without Gusts } \\
& \text { (Lbs) }
\end{aligned}
$$

$$
\begin{array}{r}
4.3 \\
53.3 \\
8.7 \\
27.8 \\
30.4 \\
.45
\end{array}
$$

With Gusts

(Lbs)

24.9

53.3

45.1

144.8

35.2

2.26

See Reference 26 for additional details. 
TABLE 7 - ASTRID I Vehicle Structural Margins of Safety

\begin{tabular}{||l|c|c||}
\hline \multicolumn{1}{|c|}{ Item } & $\begin{array}{c}\text { Without Wind Gust } \\
\text { Loading }\end{array}$ & With Wind Gust Loading \\
\hline Forward Skirt & 26.2 & 26.2 \\
\hline Forward Bolted Flange & 1.9 & 1.1 \\
\hline Forward Flange Bolts & 149 & 2.4 \\
\hline Fuel Tank & 2.8 & 6.9 \\
\hline Aft Flange Bolts & 40.5 & 0.1 \\
\hline Aft Bolted Flange & 4.0 & 1.1 \\
\hline Aft Skirt & 3.6 & 1.1 \\
\hline Thrust Plate & & \\
\hline
\end{tabular}




\section{FIG. 1. ASTRID-1 LAUNCH VEHICLE}

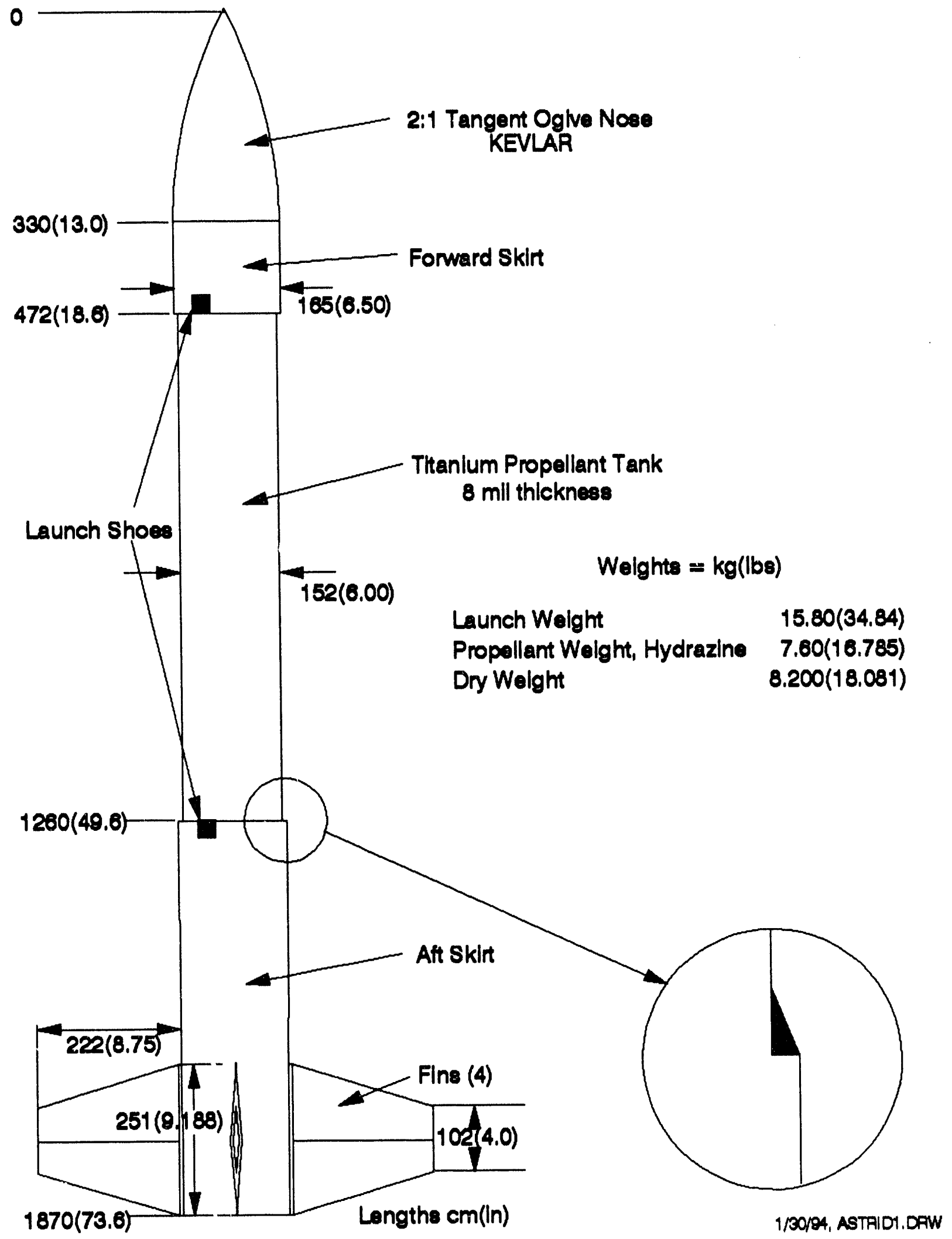




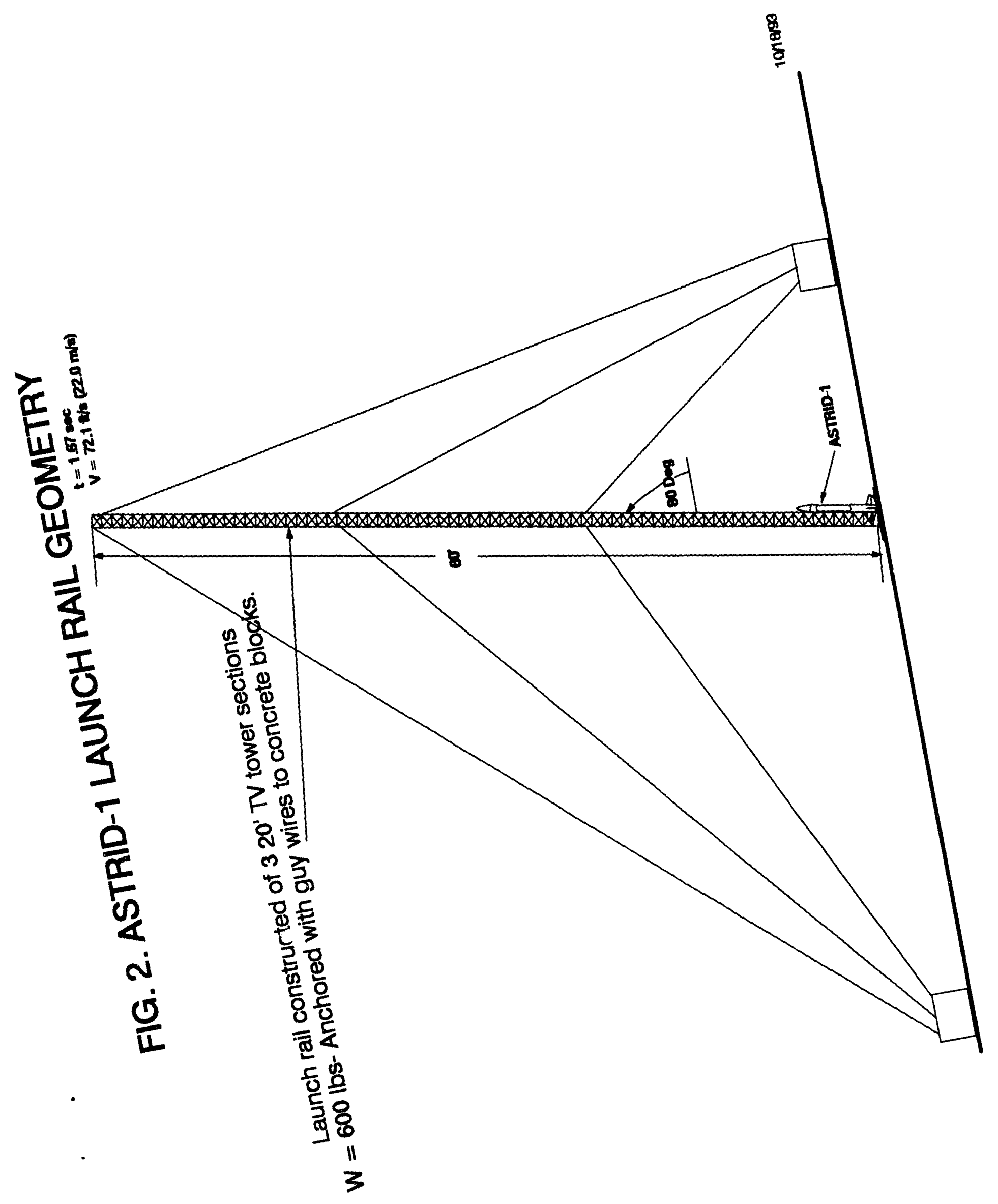




\section{FIG. 3. REAR VIEW OF ASTRID VEHICLE}

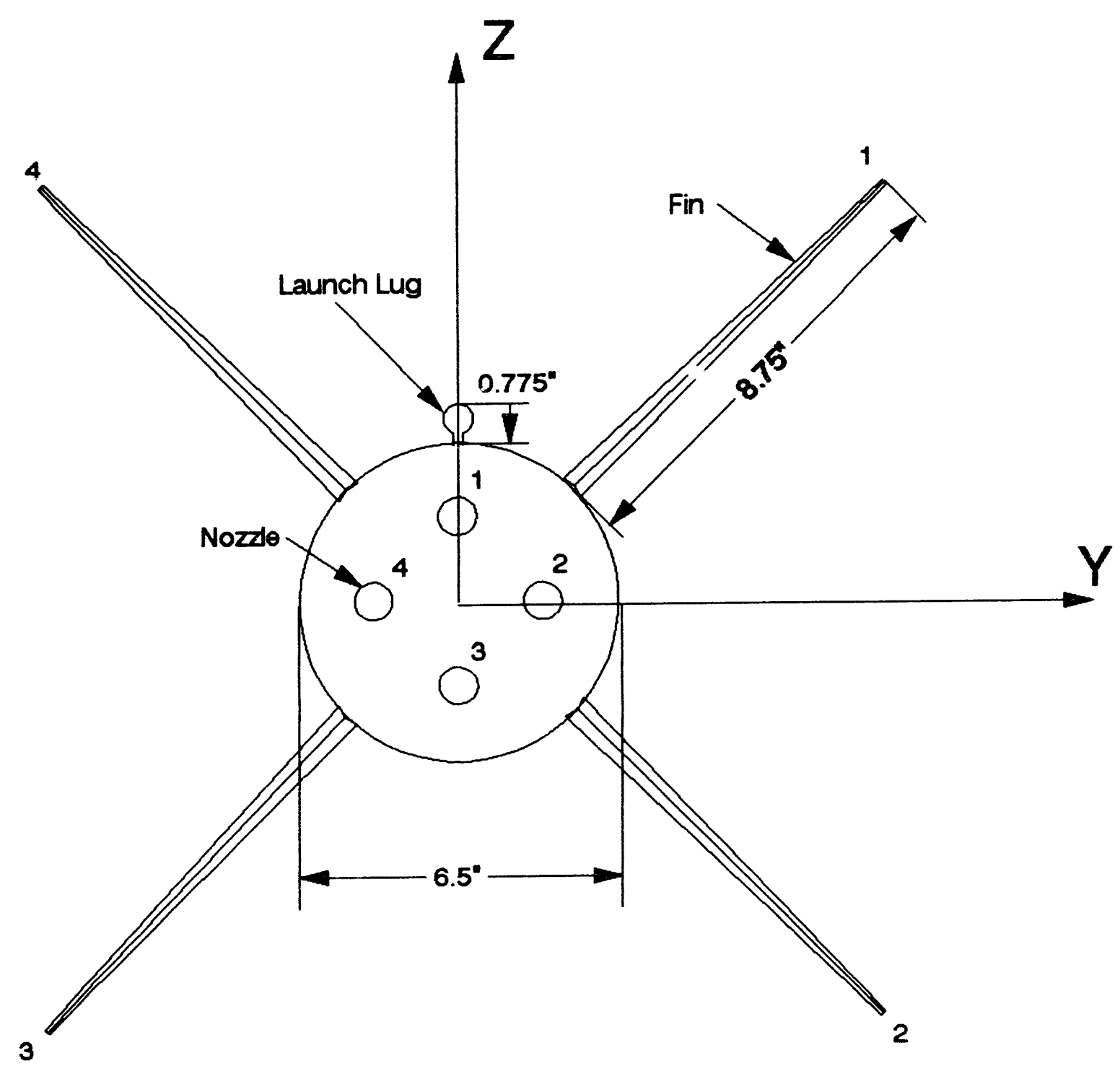


FIG. 4. ASTRID-1 VEHICLE AXIAL FORCE CONTRIBUTIONS

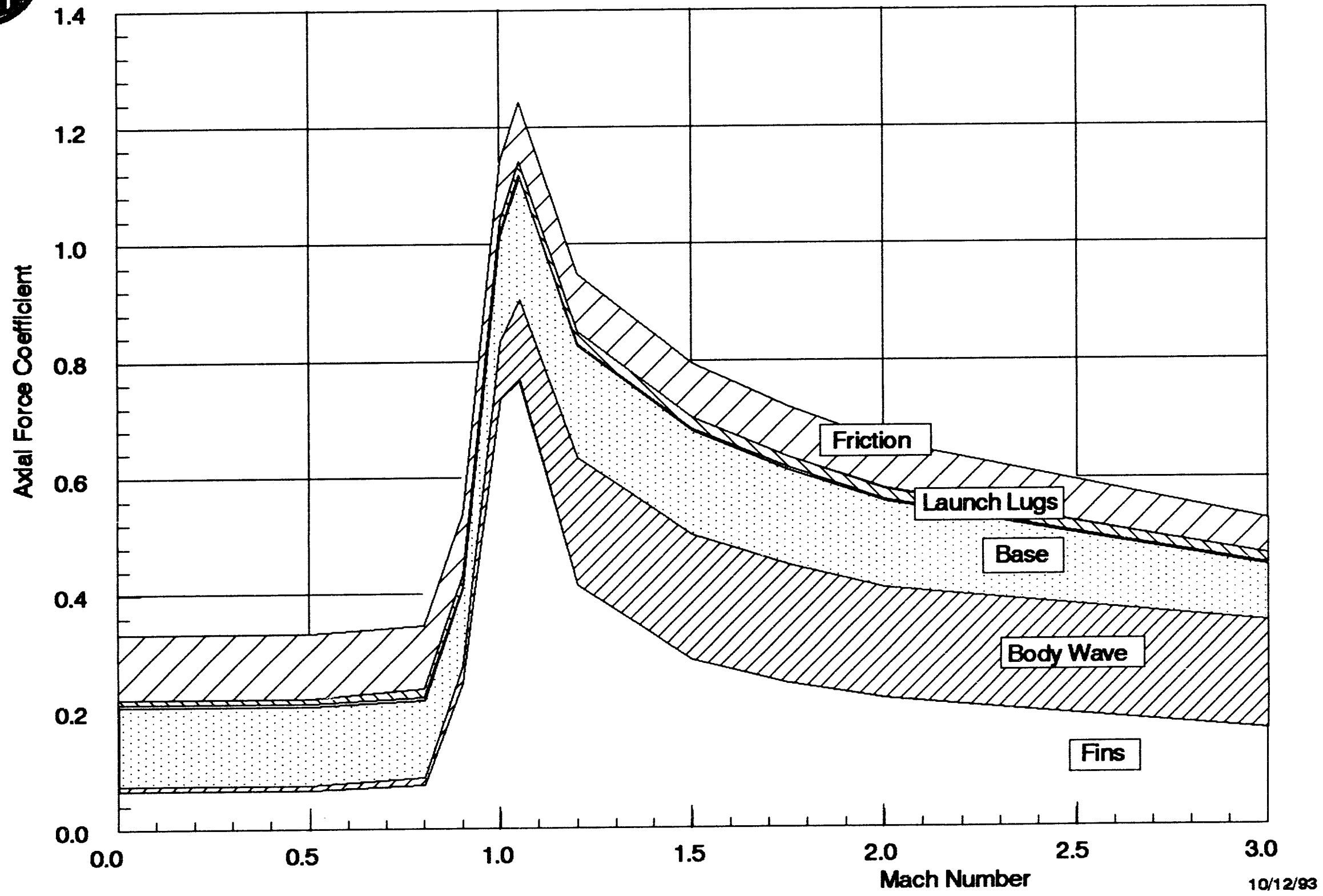


FIG. 5. ASTRID-1 FLIGHT-BASELINE TRAJECTORY

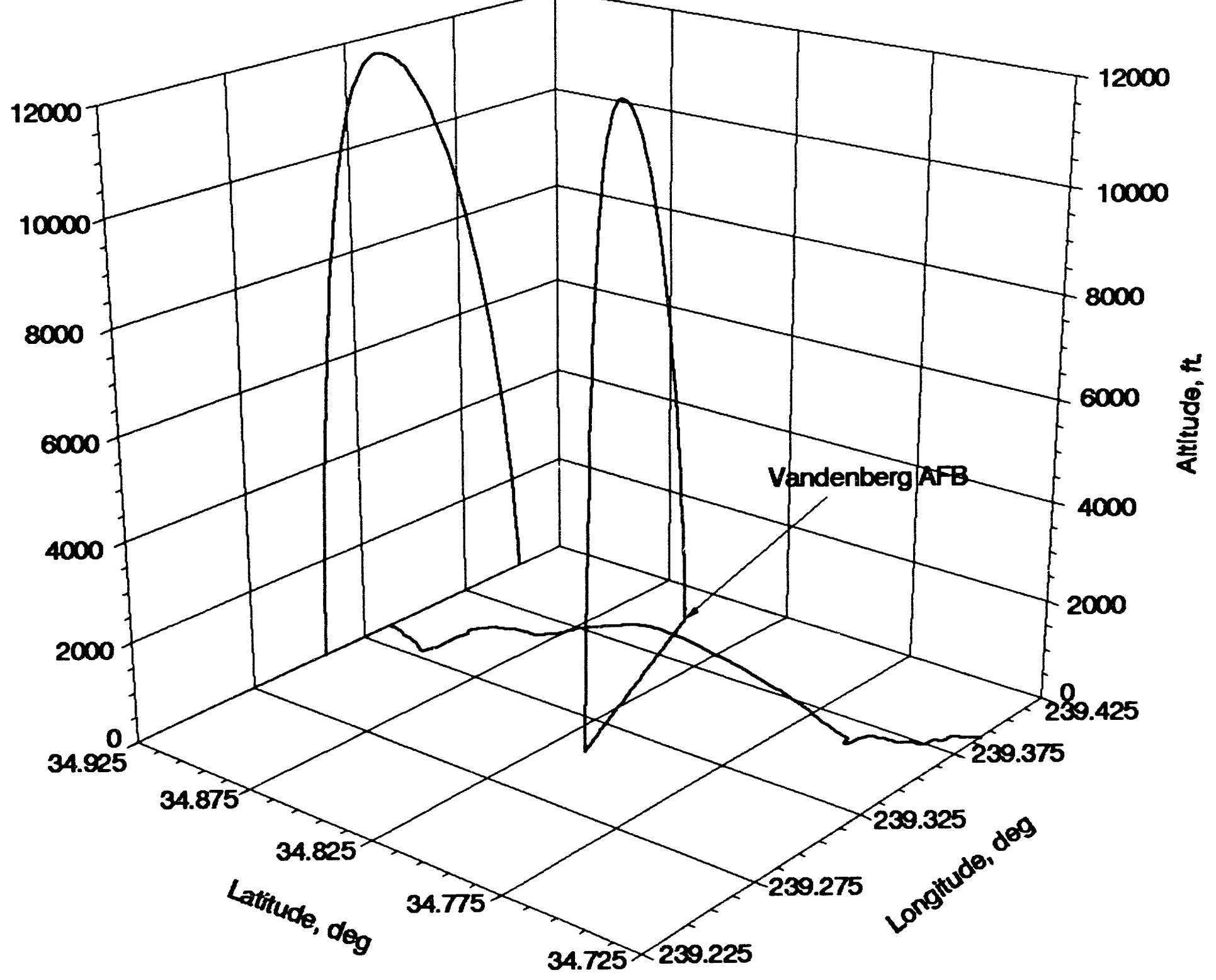




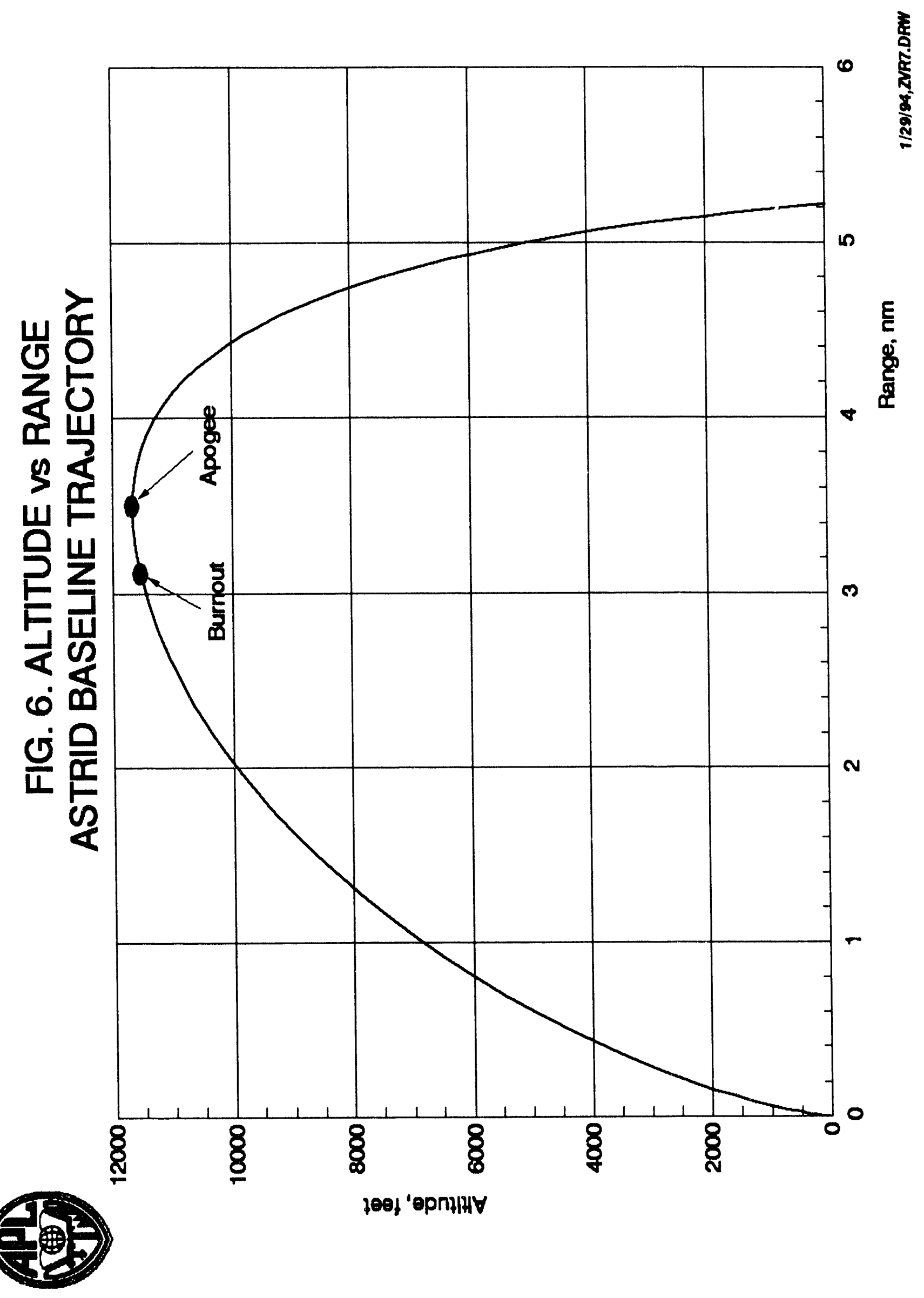




\section{FIG. 7. ASTRID BASELINE TRAJECTORY GROUND TRACK}

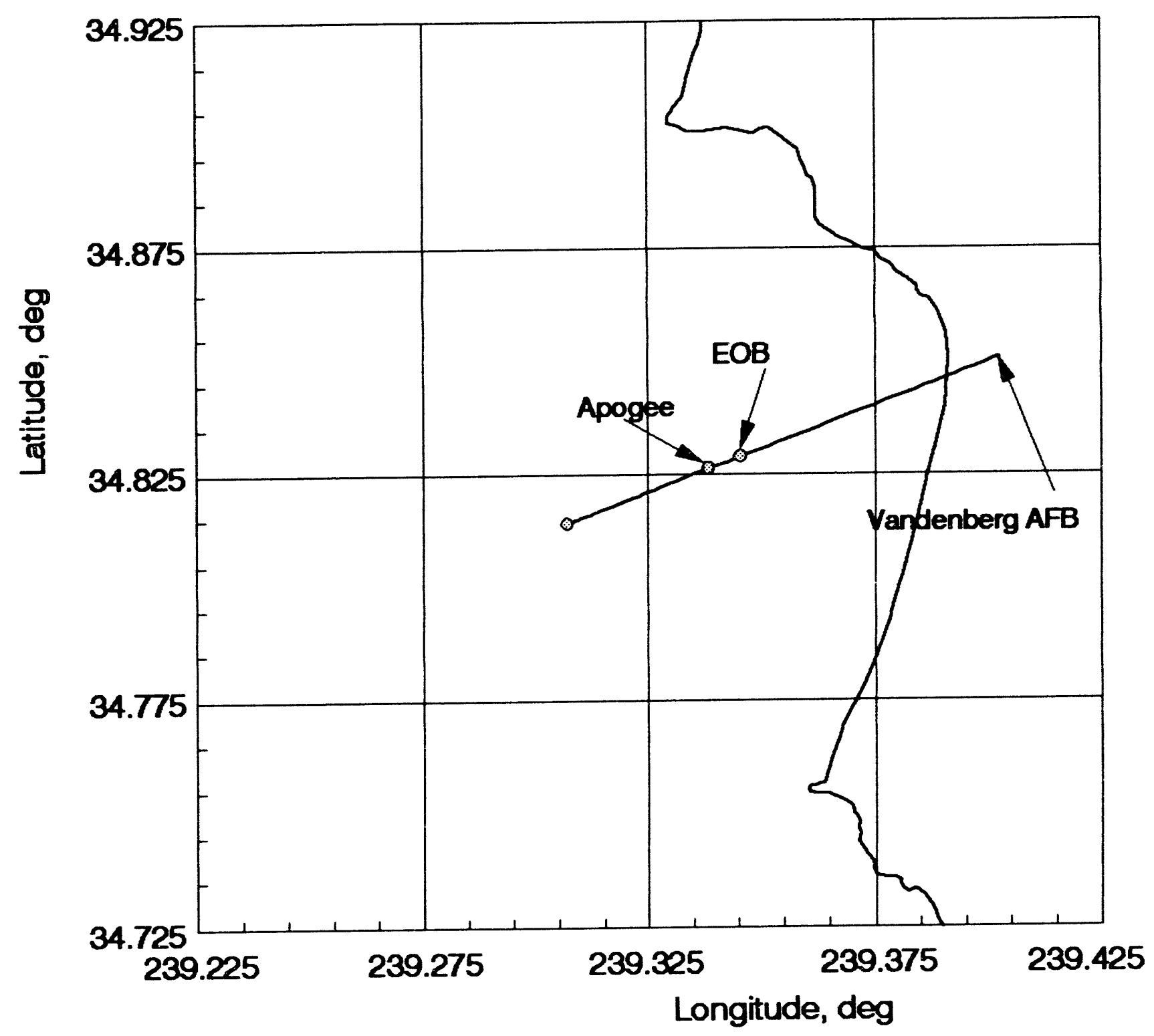




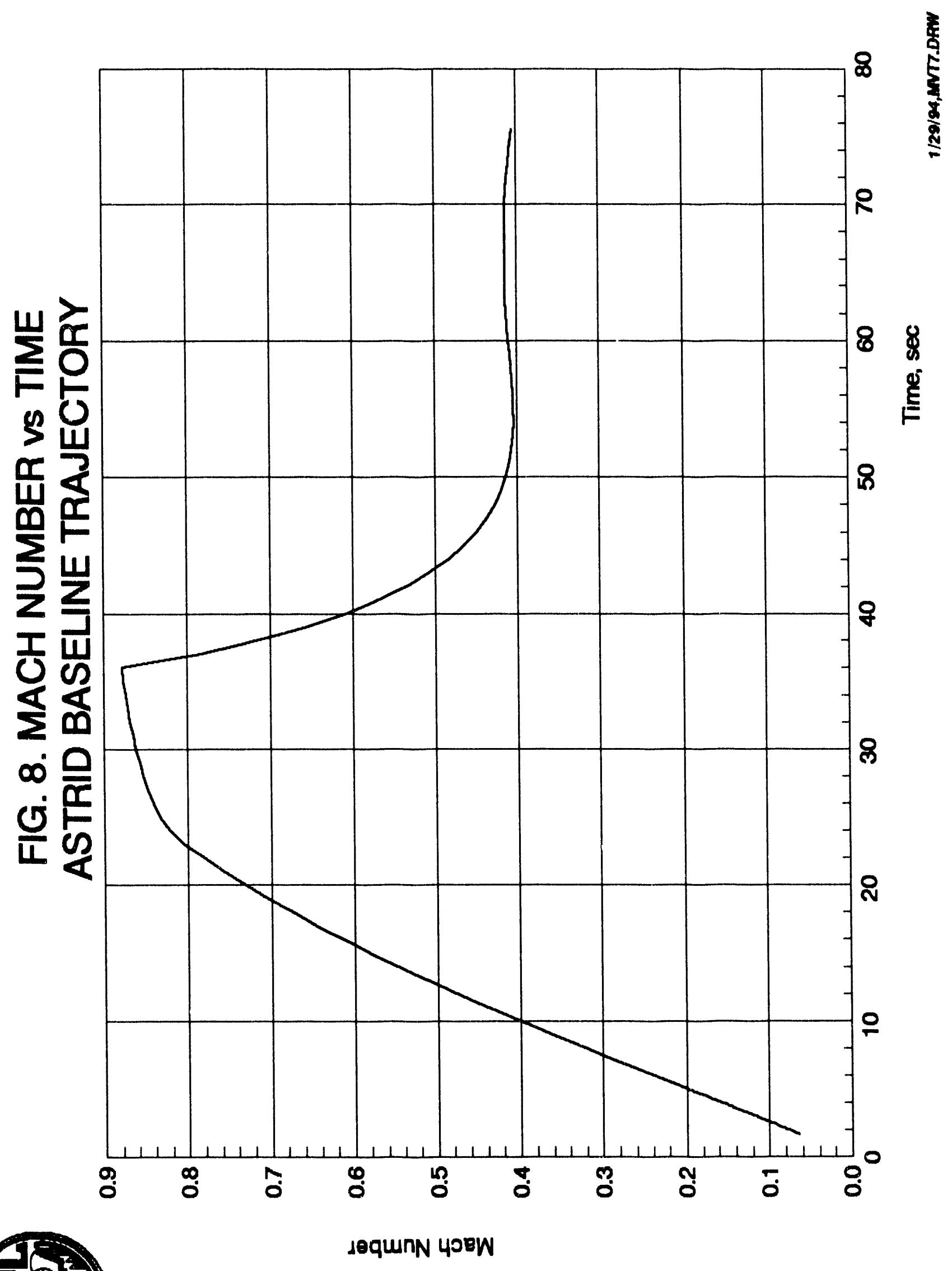


FIG. 9. DYNAMIC PRESSURE vS TIME ASTRID BASELINE TRAJECTORY

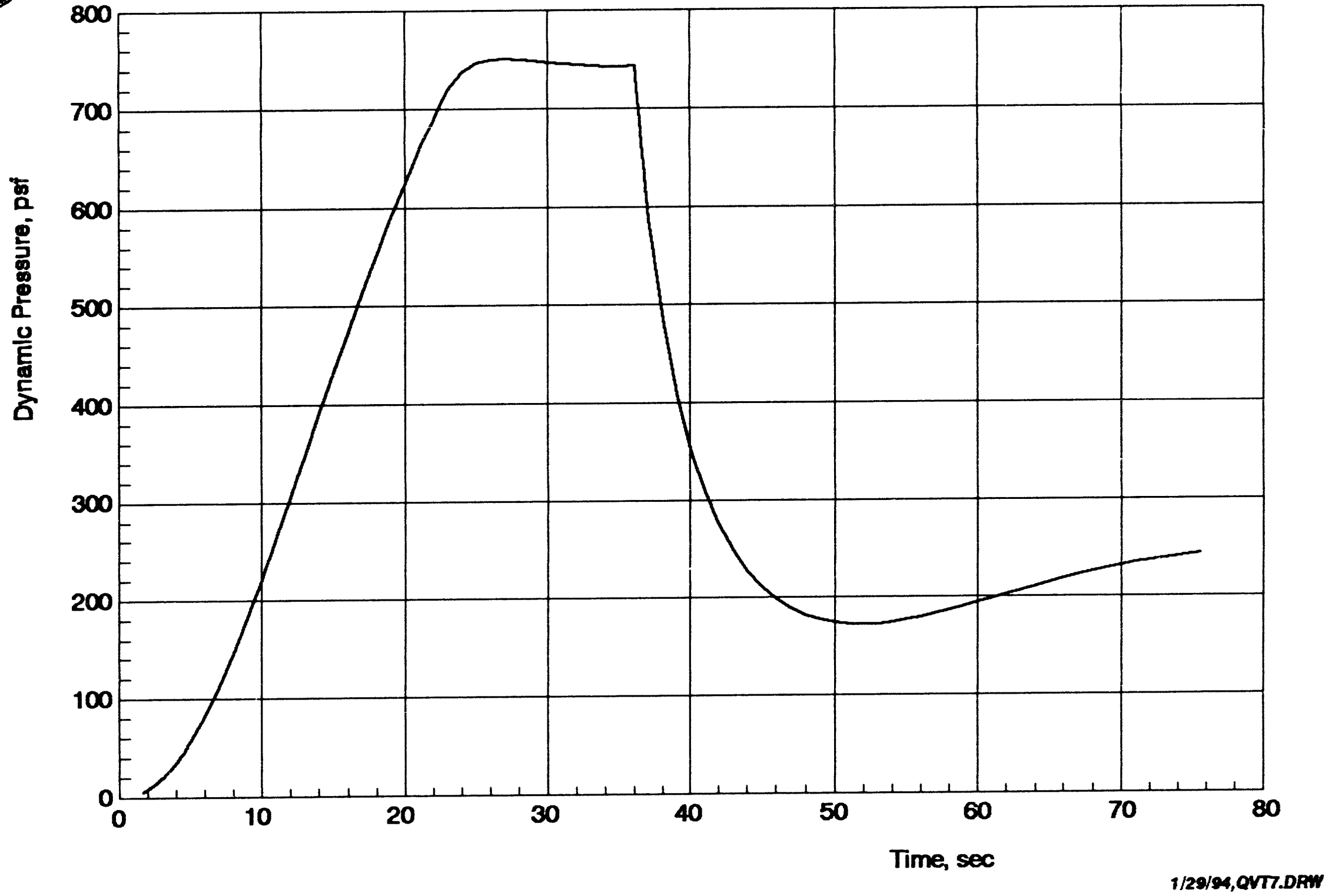


FIG. 10. AERODYNAMIC FREQUENCY AND SPIN RATE vs TIME ASTRID BASELINE TRAJECTORY

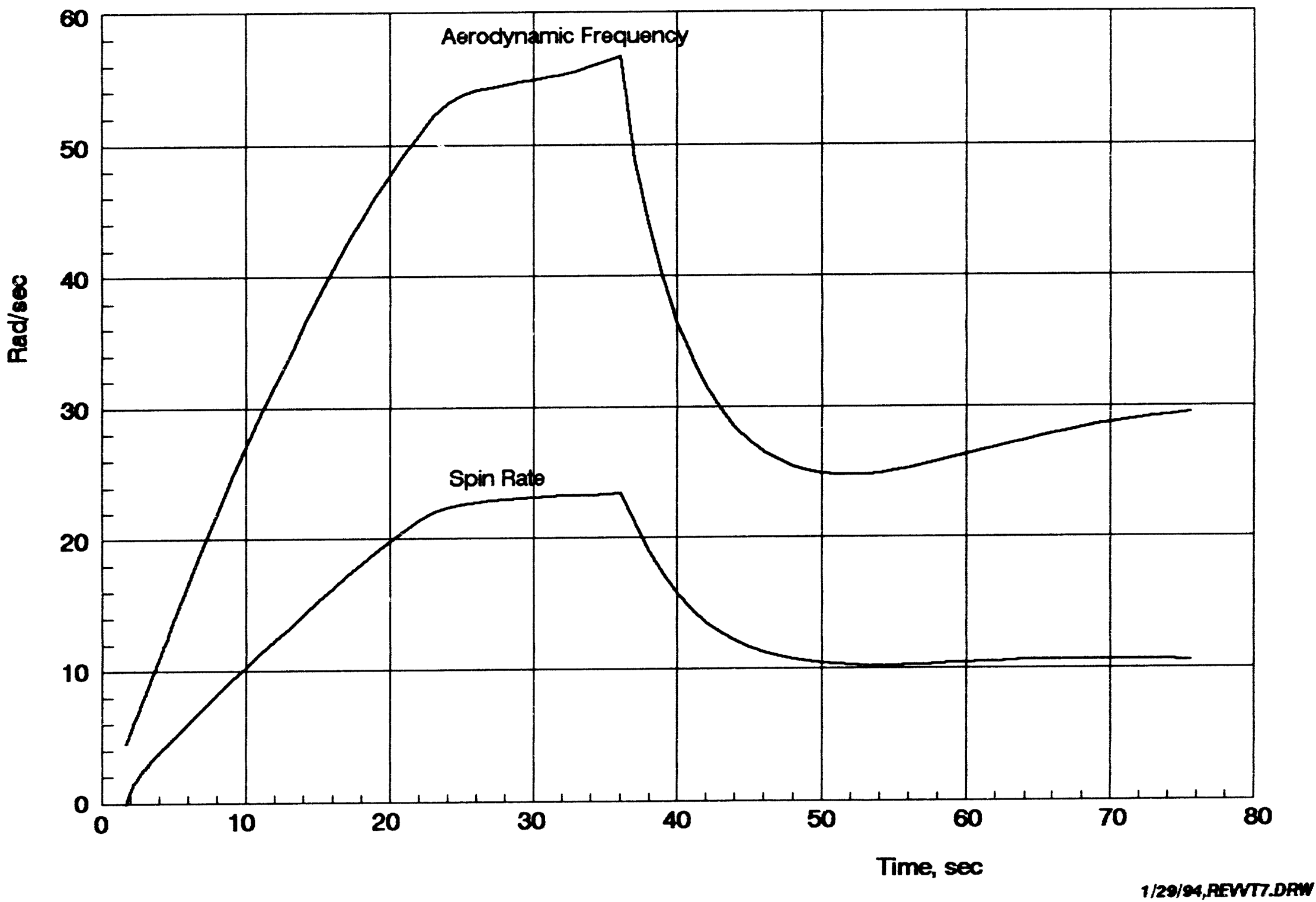


FIG. 11. ANGLE OF ATTACK \& YAW ANGLE vs TIME ASTRID BASELINE TRAJECTORY

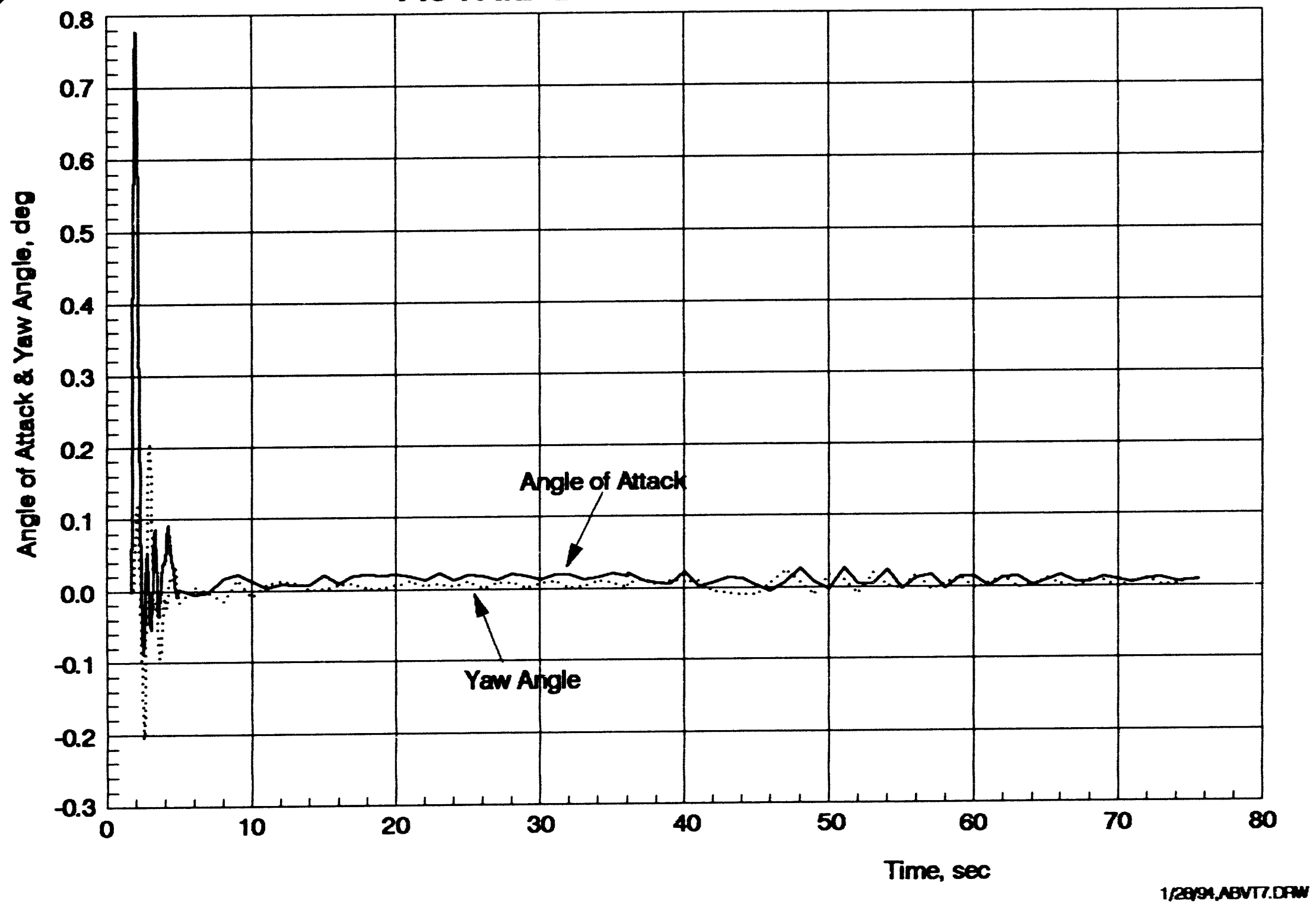


FIG. 12. FLIGHT PATH ANGLE vs TIME ASTRID BASELINE TRAJECTORY

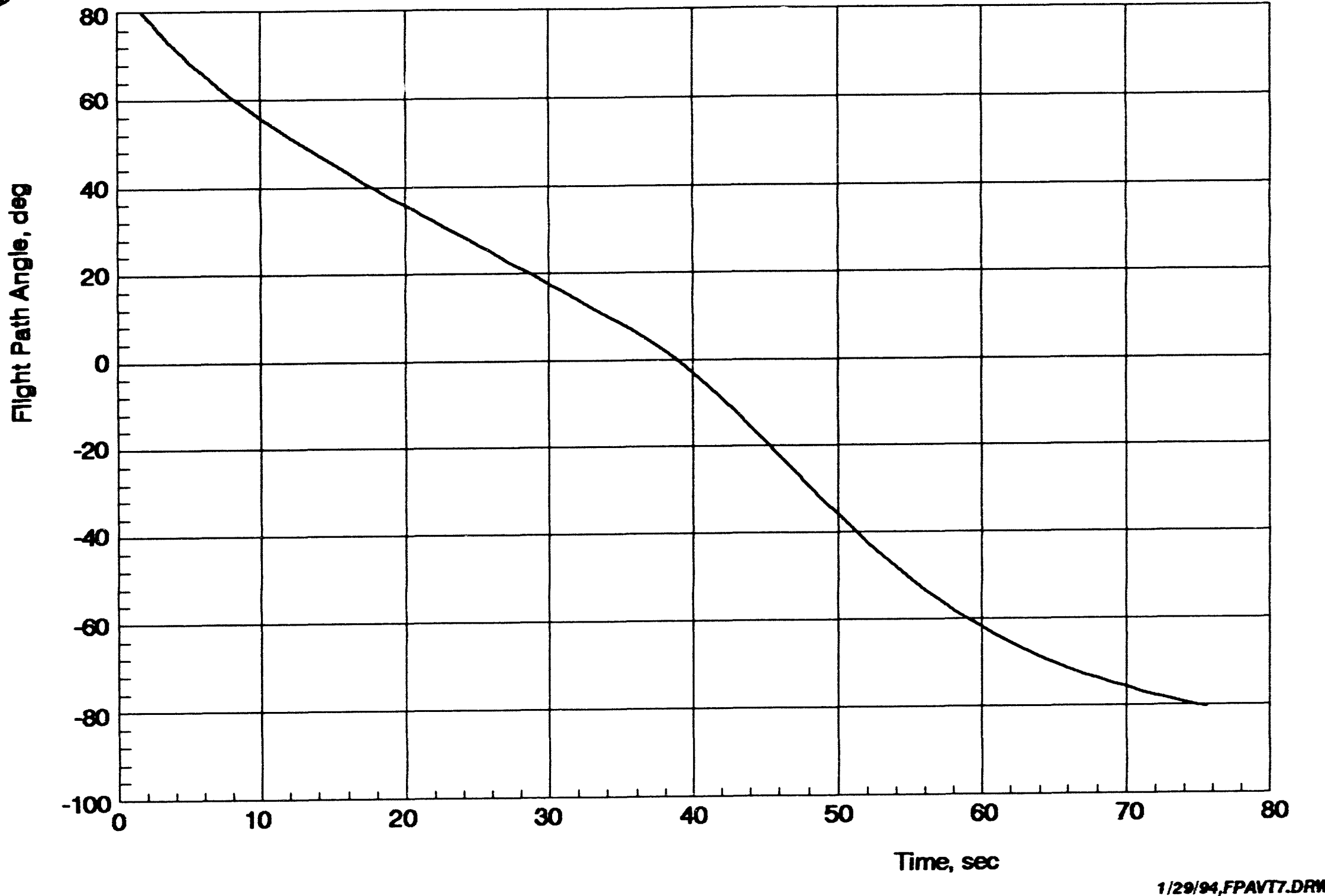


FIG. 13. RANGE vs TIME ASTRID BASELINE TRAJECTORY

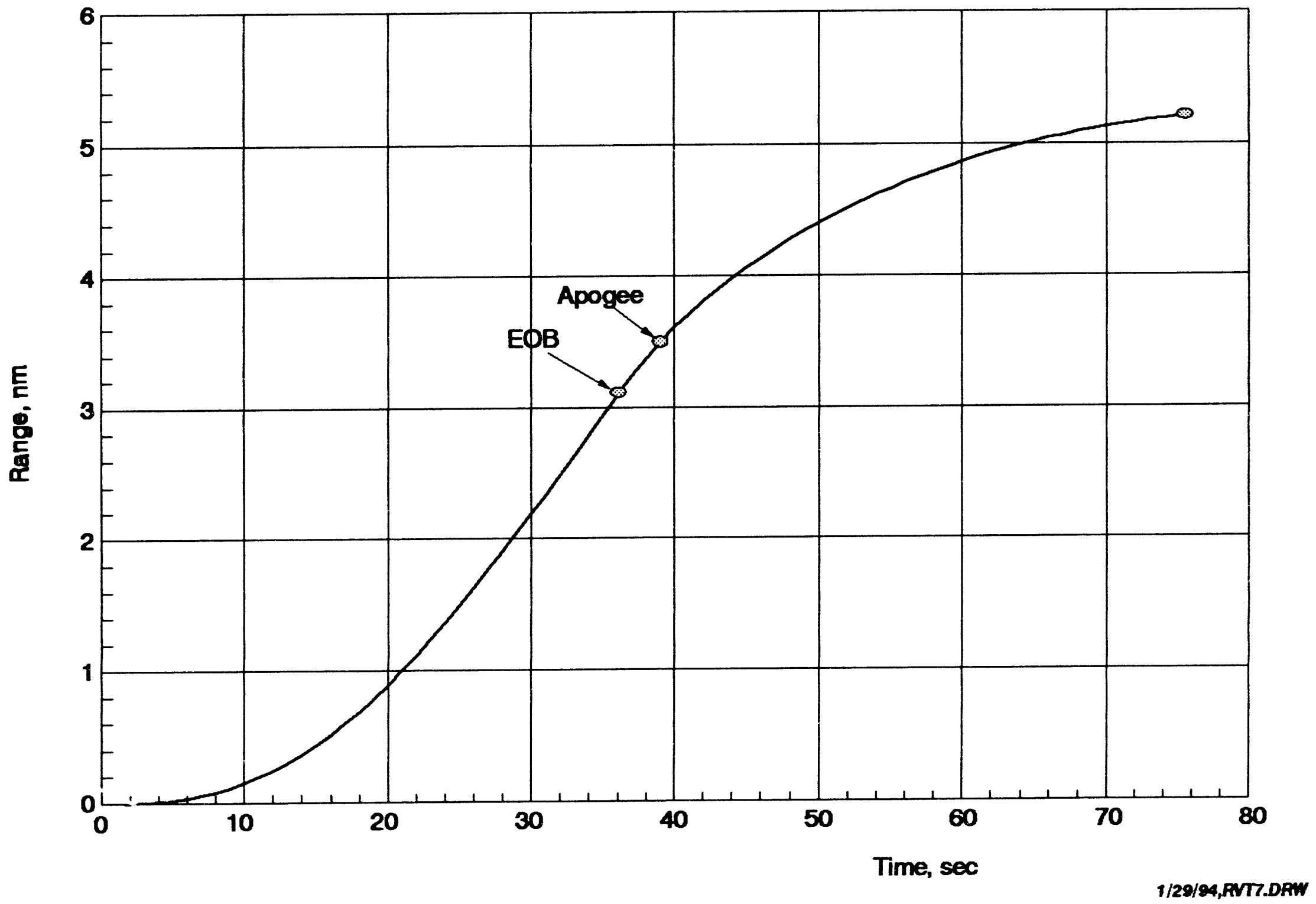


FIG. 14. ALTITUDE vs TIME ASTRID BASELINE TRAJECTORY

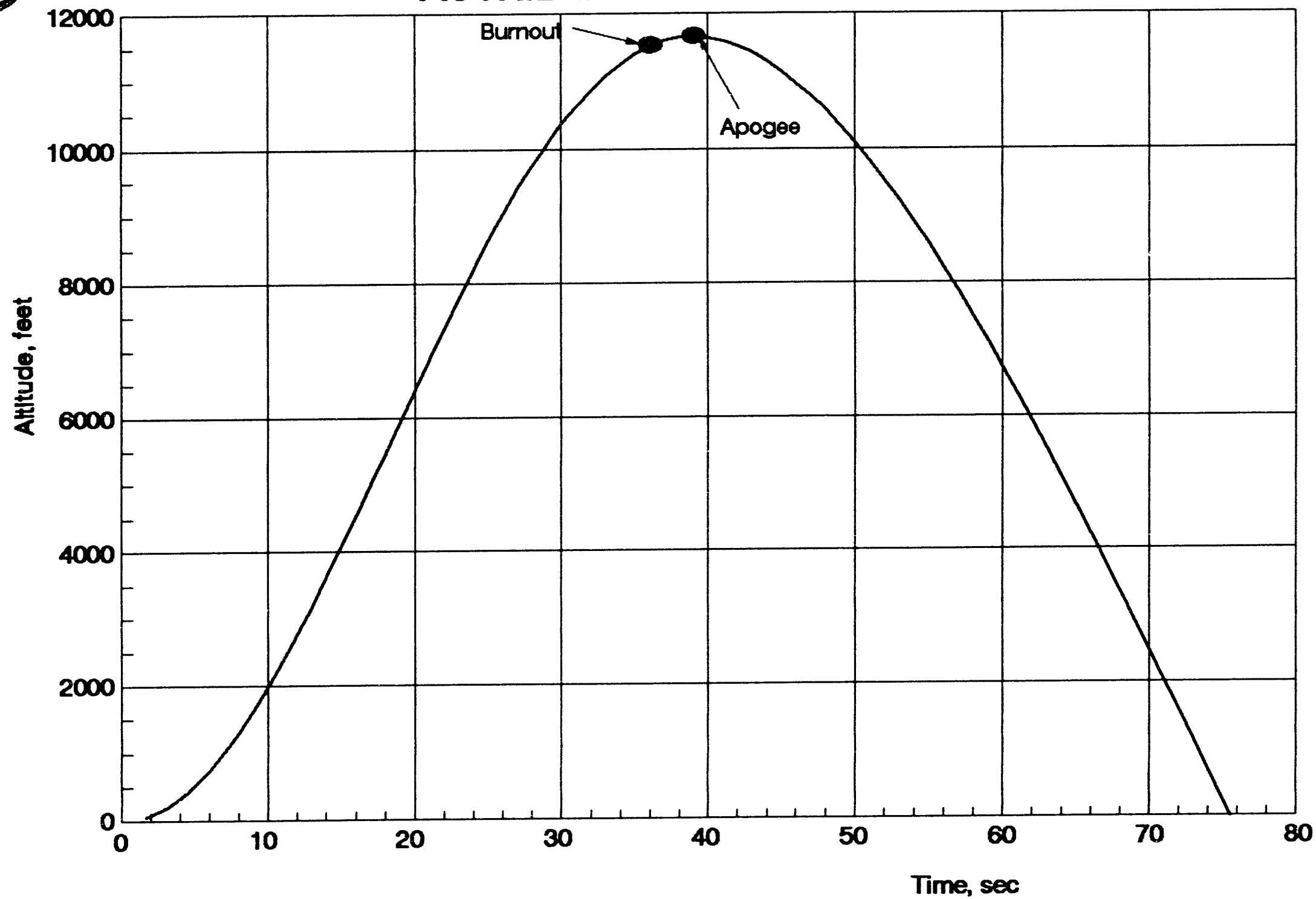




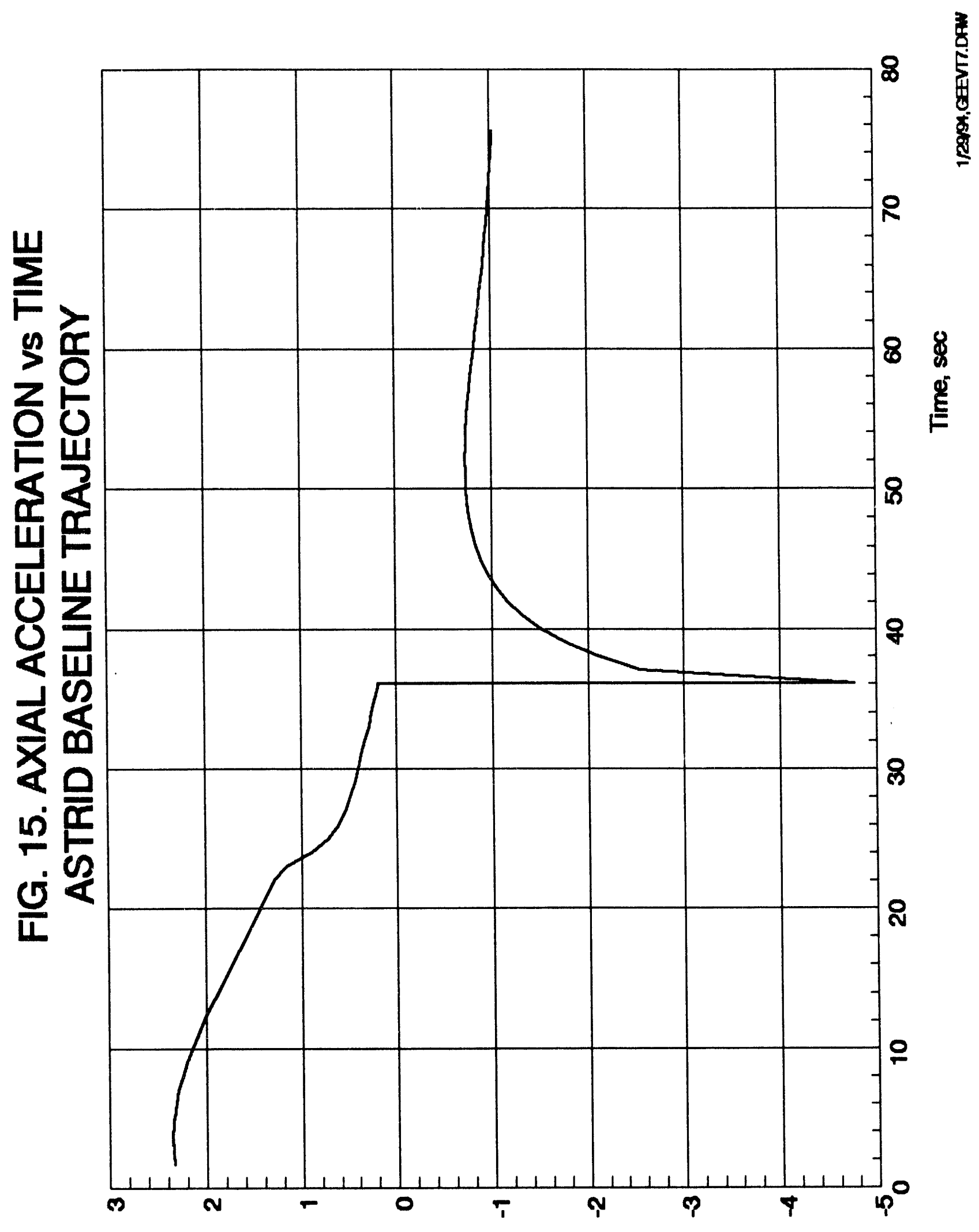

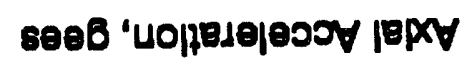




\section{FIG. 16. EFFECT OF RAIL ELEVATION ANGLE}

ON ASTRID-1 TRAJECTORY.

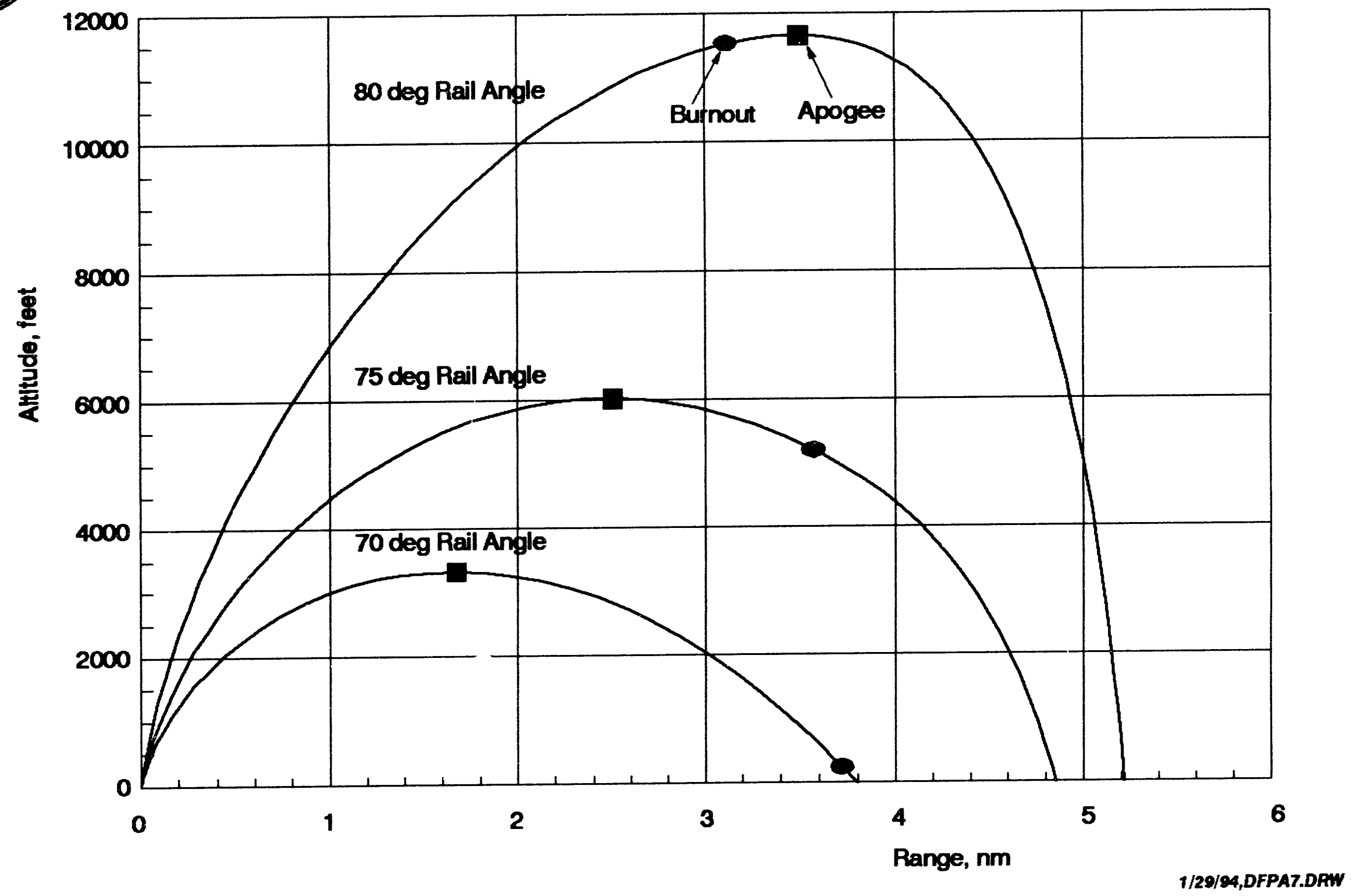


FIG. 17. VANDENBERG AFB MEAN NOVEMBER WIND SPEED

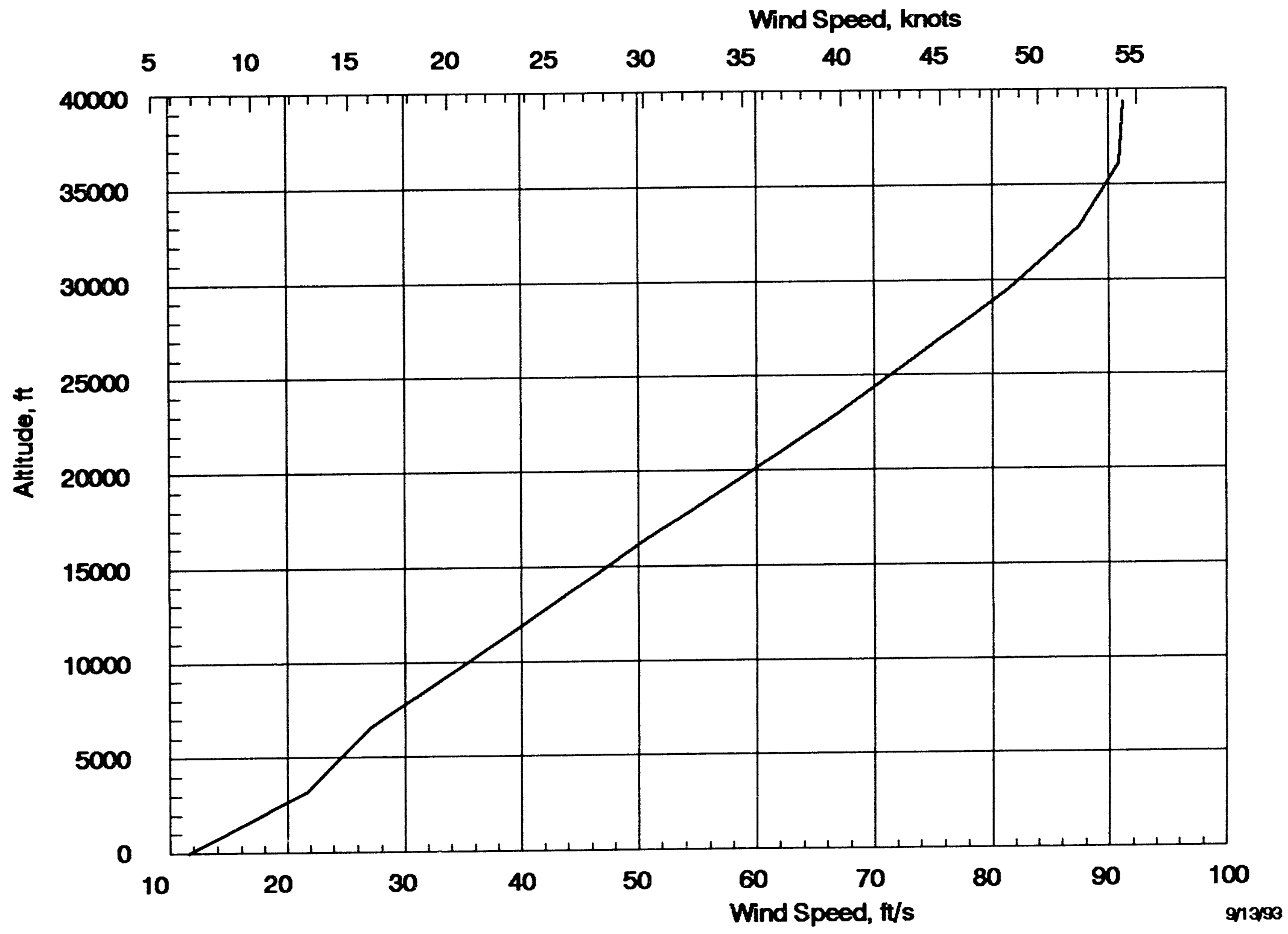




\section{FIG. 18. IMPACT POINTS OF ASTRID-1 DISPERSIONS}

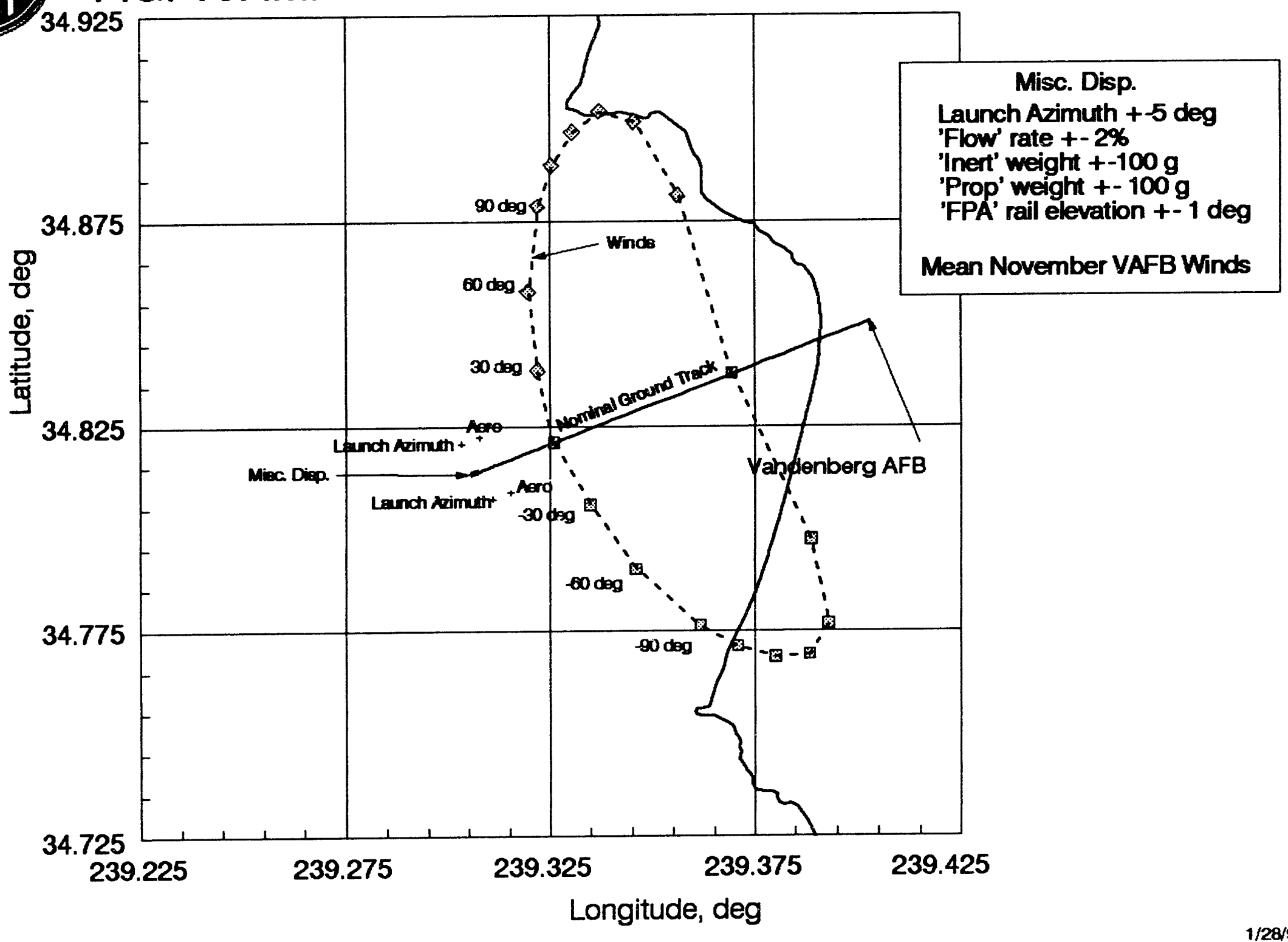


FIG. 19. ASTRID-1 DISPERSION FOOTPRINT.

$+-90 \mathrm{deg}$ Nov VAFB Winds $-0.70 \mathrm{~nm}$ Dispersions.

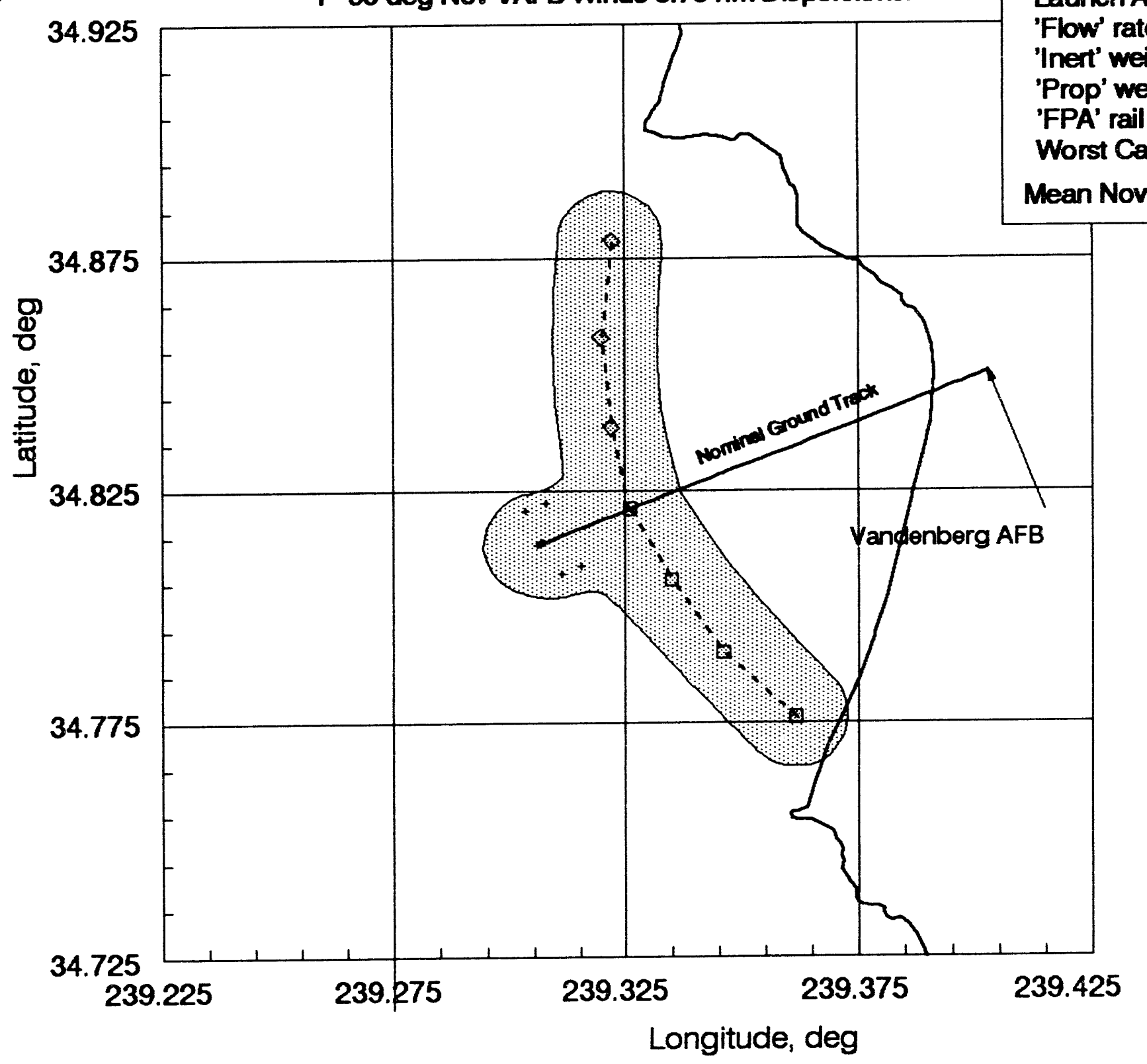


FIG. 20. BALLISTIC WIND PREDICTIONS vs 6DOF RESULTS Mean November VAFB Winds

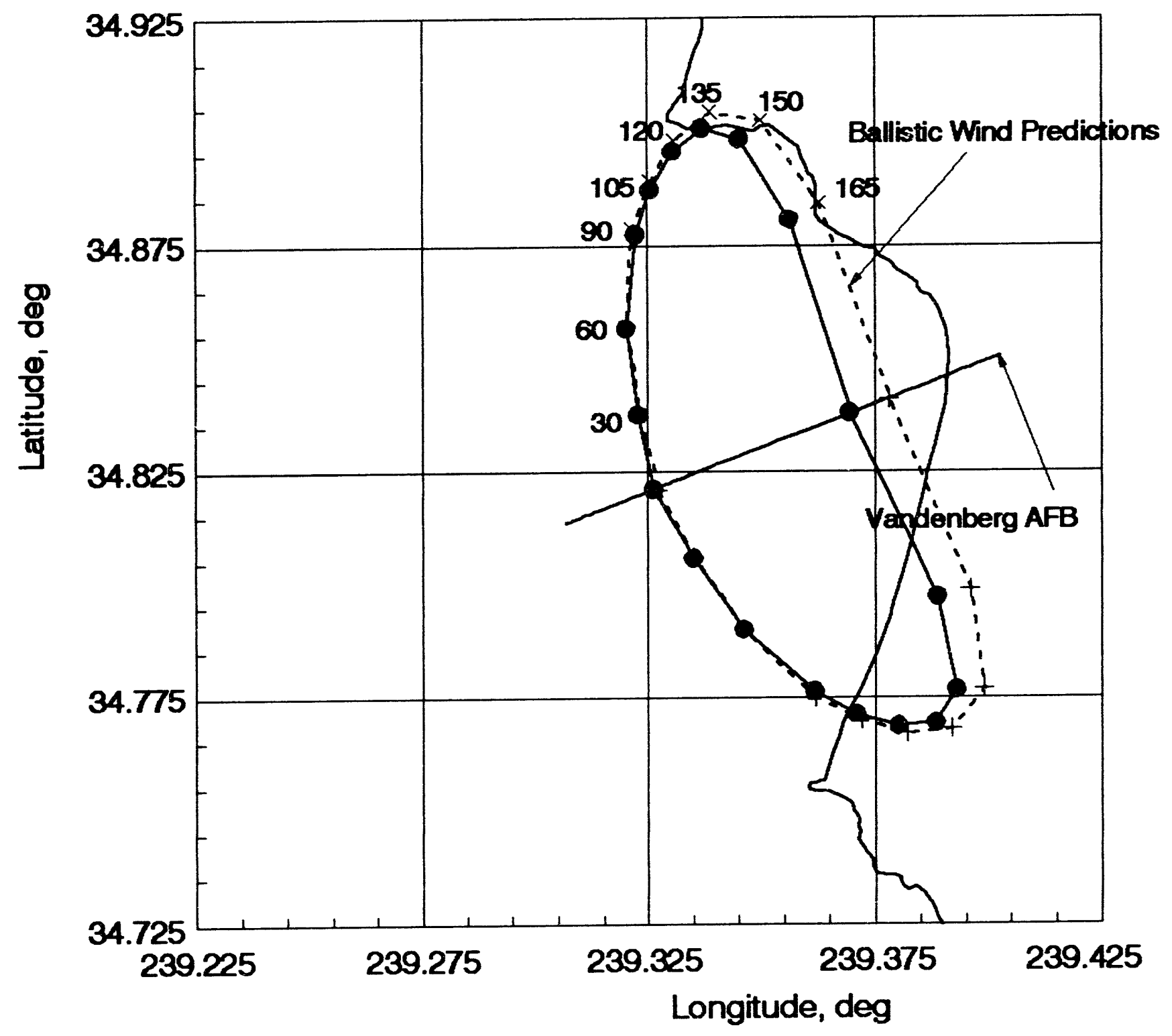




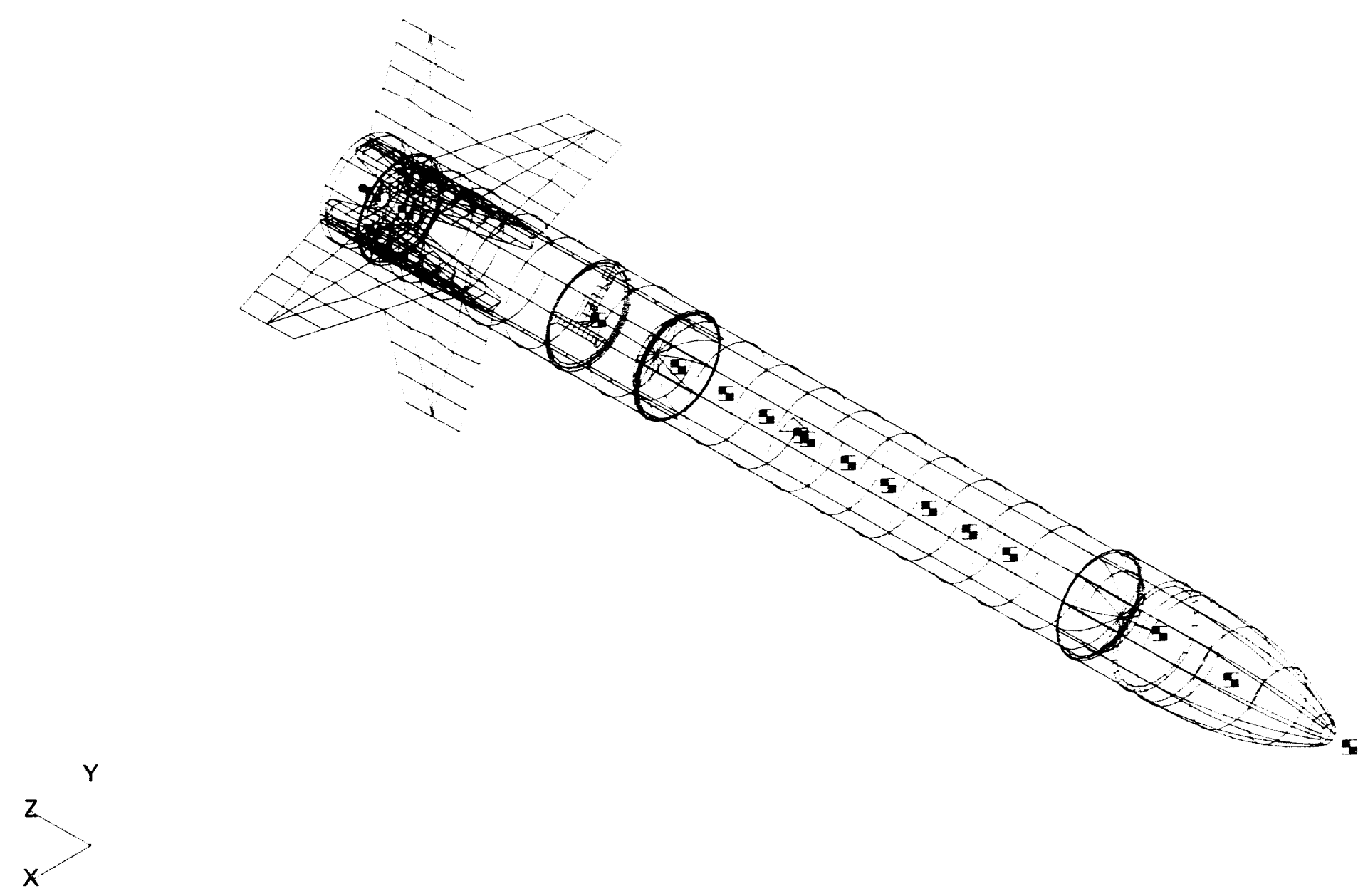




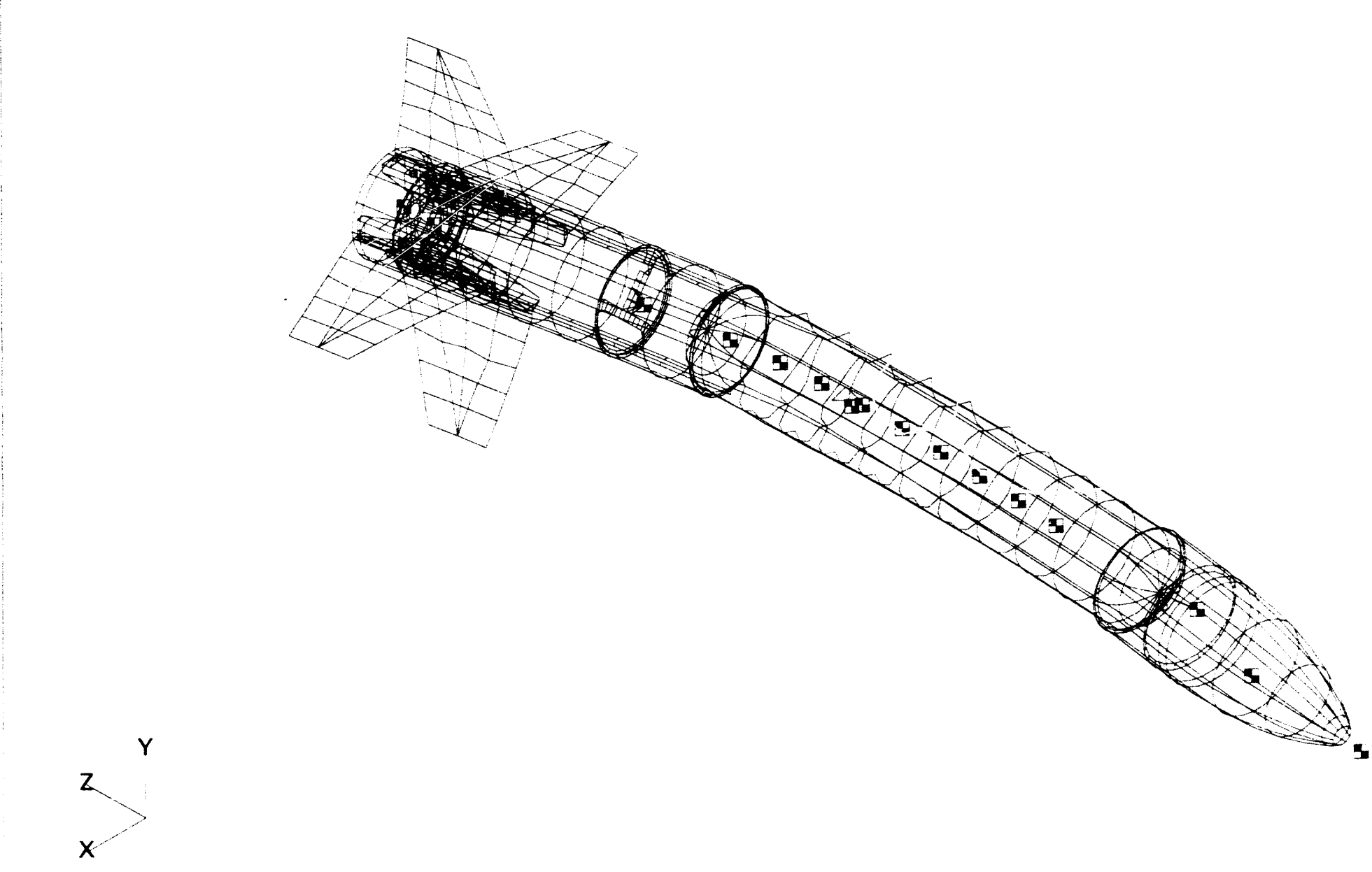

Output Set: Mode $246.54978 \mathrm{~Hz}$ Deformed(0.1): Total Translation 


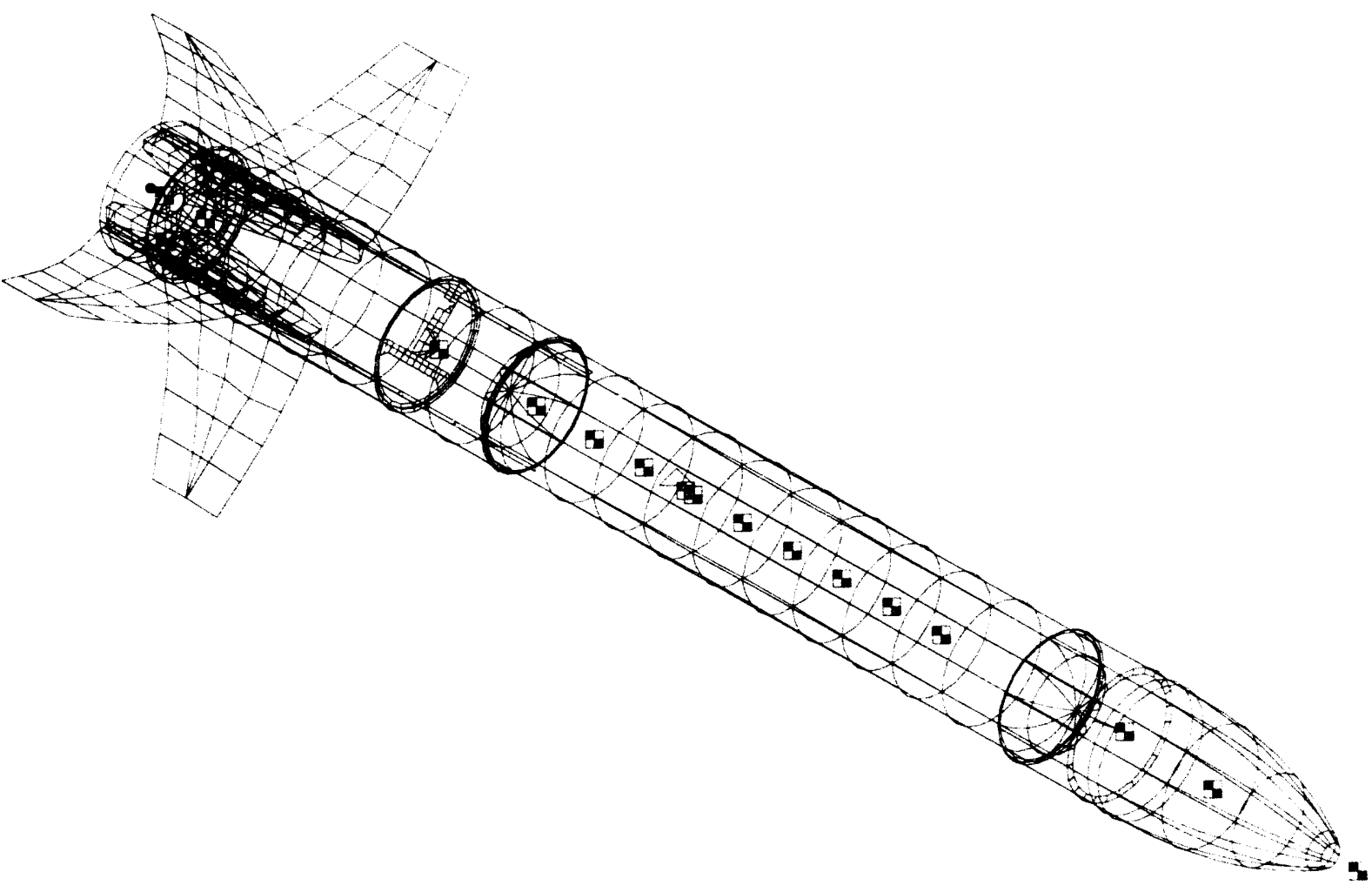

Z $x$

Output Set: Mode $480.31504 \mathrm{~Hz}$ Deformed(0.178): Total Translation 
Appendix. Nominal Trajectory Data, Position and Velocity Components, Altitude, Velocity, Ground Range, and Flight Path Angle vs Time.

Nominal Sea Level Thrust $=90$ lbs.

Range referance coordinate system, Ref. 1, WSMCR 127-1, para, 2.3.5, p2-6

\begin{tabular}{|c|c|c|c|c|c|}
\hline $\begin{array}{r}\text { Time (s) } \\
X(f t) \\
\text { Alt }(f t)\end{array}$ & $\begin{array}{l}Y(f t) \\
\operatorname{Vel}(f t / s)\end{array}$ & $\begin{array}{r}Z(f t) \\
F P A, \operatorname{deg}\end{array}$ & $\begin{array}{c}\mathrm{X}-\operatorname{dot}(\mathrm{f} / \mathrm{s}) \\
\mathrm{RN}, \mathrm{nm}\end{array}$ & $Y-\operatorname{dot}(f / s)$ & $Z \cdot \operatorname{dot}(f / s)$ \\
\hline $\begin{array}{r}1.627 \\
1.51 \\
65.66\end{array}$ & $\begin{array}{l}-0.01 \\
74.20\end{array}$ & $\begin{array}{l}65.66 \\
80.00\end{array}$ & $\begin{array}{r}12.8878 \\
0.00\end{array}$ & -0.0013 & 73.0765 \\
\hline $\begin{array}{r}2.000 \\
5.43 \\
96.04\end{array}$ & $\begin{array}{r}0.09 \\
91.53\end{array}$ & $\begin{array}{l}95.90 \\
78.73\end{array}$ & $\begin{array}{r}17.8925 \\
0.00\end{array}$ & 0.0026 & 89.7688 \\
\hline $\begin{array}{r}3.000 \\
31.75 \\
207.97\end{array}$ & $\begin{array}{r}-0.17 \\
138.54\end{array}$ & $\begin{array}{r}206.71 \\
75.21\end{array}$ & $\begin{array}{r}35.3603 \\
0.01\end{array}$ & -0.1193 & 133.9513 \\
\hline $\begin{array}{r}4.000 \\
77.74 \\
363.60\end{array}$ & $\begin{array}{r}0.27 \\
186.21\end{array}$ & $\begin{array}{r}363.55 \\
72.01\end{array}$ & $\begin{array}{r}57.5148 \\
0.01\end{array}$ & -0.0547 & 177.1084 \\
\hline $\begin{array}{r}5.000 \\
148.32 \\
561.73\end{array}$ & $\begin{array}{r}-0.19 \\
234.24\end{array}$ & $\begin{array}{r}560.99 \\
69.13\end{array}$ & $\begin{array}{r}83.4513 \\
0.02\end{array}$ & -0.0932 & 218.8743 \\
\hline $\begin{array}{r}6.000 \\
246.10 \\
800.77\end{array}$ & $\begin{array}{r}0.15 \\
282.34\end{array}$ & $\begin{array}{r}800.14 \\
66.47\end{array}$ & $\begin{array}{r}112.7210 \\
0.04\end{array}$ & -0.0763 & 258.8679 \\
\hline $\begin{array}{r}7.000 \\
374.45 \\
1078.77\end{array}$ & $\begin{array}{r}0.59 \\
330.21\end{array}$ & $\begin{array}{r}1078.71 \\
63.98\end{array}$ & $\begin{array}{r}144.8740 \\
0.06\end{array}$ & -0.0398 & 296.7345 \\
\hline $\begin{array}{r}8.000 \\
536.43 \\
1393.46\end{array}$ & $\begin{array}{r}0.25 \\
377.55\end{array}$ & $\begin{array}{r}1392.70 \\
61.63\end{array}$ & $\begin{array}{r}179.3908 \\
0.09\end{array}$ & 0.0123 & 332.2061 \\
\hline $\begin{array}{r}9.000 \\
734.34 \\
1742.33 \\
10.000\end{array}$ & $\begin{array}{r}0.66 \\
424.11\end{array}$ & $\begin{array}{r}1741.53 \\
59.40\end{array}$ & $\begin{array}{r}215.9087 \\
0.12\end{array}$ & -0.0217 & 365.0353 \\
\hline $\begin{array}{r}968.58 \\
2122.60\end{array}$ & $\begin{array}{r}0.15 \\
469.64\end{array}$ & $\begin{array}{r}2122.36 \\
57.26\end{array}$ & $\begin{array}{r}253.9914 \\
0.16\end{array}$ & 0.0547 & 395.0378 \\
\hline $\begin{array}{r}11.000 \\
1242.03 \\
2531.41\end{array}$ & $\begin{array}{r}0.65 \\
513.96\end{array}$ & $\begin{array}{r}2530.91 \\
55.20\end{array}$ & $\begin{array}{r}293.3158 \\
0.20\end{array}$ & 0.0949 & 422.0370 \\
\hline
\end{tabular}


12.000 1555.72

2965.72

13.000

1909.22

3422.46

14.000

2304.62

3898.47

15.000

2740.17

4390.62

16.000

3216.66

4895.80

17.000

3733.80

5411.00

18.000

4290.98

5933.32

19.000

4888.15

6459.99

20.000

5523.54

6988.35

21.000

6197.66

7515.90

22.000

6907.79

8039.34

23.000

7647.50

8552.73

24.000

8413.18

9051.34
$-0.06$

556.91

2965.48
53.22

333.4954

0.26

$-0.29$

598.33

3421.82

51.29

374.1897

0.31

$-0.09$

638.08

3897.78
49.42

415.1368

0.38

$-0.58$

4390.25

47.58

456.1371

0.45

0.1817

499.0955

676.13

$-0.70$

712.46

4894.85
45.79

496.8866

0.53

$0.1115 \quad 510.5936$

$-0.63$

747.09

5409.88

44.03

537.2258

0.61

0.1174

519.1595

$-0.74$

780.09

5931.92
42.30

577.1195

0.71

$-0.53$

811.52

6458.59
40.58

616.4401

0.80

0.1181

527.7930

$-1.14$

6986.76
38.89

655.0634

0.91

841.46

$-1.23$

869.99

7515.02

37.23

692.8291

1.02

0.1648

526.1794

$-1.57$

892.78

8037.44
35.57

726.3763

1.14

$-1.44$

907.87

8550.98

33.92

753.5211

1.26

0.0879

506.3907

$-1.70$

9049.28

32.26

776.6540

1.38

$0.1981 \quad 519.0738$

918.21

0.2240

489.8083

(32.

\author{
1.38
}


Ipplicel Phosic L aboralom

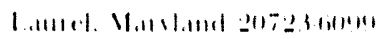

25.000

9200.55

9532.08

$-2.20$

9529.55

30.58

797.2074

925.74

$-1.84$

931.64

9990.41

28.89

815.8790

1.65

$-2.38$

936.52

10428.60

27.19

833.2755

1.78

28.000

11673.06

10848.05

29.000

12531.25

11240.23

30.000

13403.44

11607.44

31.000

14289.71

11948.81

32.000

15189.31

12263.54

33.000

16101.78

12550.88

34.000

17025.21

12810.14

35.000

17959.25

13040.51

36.000

18900.62

13241.22

37.000

19848.42

13411.76

$\begin{array}{ll}-2.30 & 11236.17\end{array}$ $\begin{array}{lll}-1.78 & 10844.14 & 849.6684\end{array}$

$\begin{array}{lll}940.74 & 25.45 & 1.92\end{array}$

$944.56 \quad 23.71$

865.0671

2.06

$-0.0009 \quad 379.2734$

$-2.16 \quad 11602.59$

879.5831

2.20

0.0125

353.9416

$948.12 \quad 21.96$

$-2.78 \quad 11943.54$

951.49

20.18

893.2953

2.35

0.1323

327.6304

$-2.18$

12257.76

18.38

906.1756

2.50

$0.1091 \quad 300.4356$

954.68

$-2.63$

957.73

12544.40

918.1069

2.65

$-0.0314$

272.6174

16.58

2.65

$-2.92$

12802.48

929.0280

2.80

$-0.0864$

244.2621

960.60

14.78

$-2.30$

13032.57

937.7145

2.95

$-0.0023$

214.9417

962.03

12.96

$-1.94$

13232.45

11.12

944.9150

0.0926

184.8735

962.83

3.11

$-1.93$

13401.68

9.27

951.0666

3.26
$0.0553 \quad 154.3466$ 
Applied Phesics Taboratery

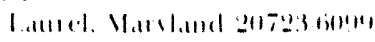

38.000

20802.39

13551.76

38.935

21697.94

13654.75

38.935

21697.94

13654.75

39.000

21760.53

13660.87

40.000

22648.87

13732.41

41.000

23455.28

13767.07

42.000

24196.45

13768.66

43.000

24882.91

13739.73

44.000

25522.85

13682.31

45.000

26120.86

13598.02

46.000

26684.21

13488.22

47.000

27214.36

13354.09

48.000

27714.37

13196.69
$-2.93$

964.15

13540.98

7.42

956.2020

3.42

$-2.50$

13642.96

5.70

960.0569

3.57

$-2.50 \quad 13642.96$

964.72

5.70

960.0569

3.57

$-0.0283$

94.7528

$-2.34$

13649.25

5.57

949.4655

3.58

$-2.35$

13719.42

3.55

841.8599

3.73

$-2.17$

771.73

13753.62

1.32

771.5521

3.86

$-2.57$

13754.23

$-1.12$

712.5311

3.98

0.0165

$-14.8014$

712.68

$-2.52$

13724.55

$-3.76$

662.1086

4.09

0.0644

$-44.2917$

663.58

$-2.04$

622.53

13666.08

$-6.56$

618.3728

4.20

$-2.03$

13581.02

$-9.52$

579.9183

4.30

$-2.61$

559.38

13470.44

$-12.62$

545.7183

4. 39

$-2.83$

13335.75

514.9652

4.48

535.43

$-15.82$

$-3.14$

13177.63

$-19.10$

487.0060

4.56
0.1313

$-122.8769$

$0.0206 \quad-71.8204$

$0.0557 \quad-98.0186$

$0.1753-146.6294$

$0.2004 \quad-169.3931$ 
Applied Phasion lathoratom

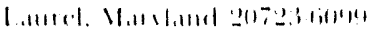

49.000

28188.75

13016.98

50.000

28638.45

12815.88

51.000

29064.97

12594.27

52.000

29469.56

12353.01

53.000

29853.93

12092.96

54.000

30220.33

11814.99

55.000

30567.73

11519.94

56.000

30898.45

11208.71

57.000

31212.62

10882.20

58.000

31511.48

10541.29

59.000

31794.43

10186.91

60.000

32063.13

9819.98

61.000

32317.39

9441.41

$$
-3.03
$$

499.39

12998.16

$-22.44$

461.3392

4.64

-3.34
486.30

12795.50
-25.78

437.5971

4.71

-3.58
475.95

12573.44

$-29.11$

415.4977

4.78

$-4.42$

12331.84

$-32.40$

394.7599

4.85

462.07

12071.40

$-35.63$

375.1808

4.91

$-4.99$

11792.52

$-38.76$

356.6658

4.97

457.91

$-4.44$

455.23

11496.90

$-41.77$

339.0694

5.03

$-5.94$

453.77

11185.09

.44 .67

322.2167

5.08

$-6.51$

10858.51

$-47.44$

306.1055

453.30

$-6.77$

453.60

10517.00
-50.06

290.6971

5.18

$-6.67$

10161.85

275.8341

454.50

$-52.55$

$-8.04$

9794.74

261.5287

455.81

$-54.90$

$-8.10$

9415.38

247.8392

457.42
5.13

5.23

5.27

0.2088

$-191.2074$

$\begin{array}{ll}0.2219 & -212.1099\end{array}$

$0.2684 \quad-232.1294$

$0.3520 \quad-251.3267$

$0.3811 \quad-269.7168$

$0.3651 \quad-287.1872$

$0.4290 \quad-303.7511$

$0.5013 \quad-319.5027$

$0.4865 \quad-334.3401$

$0.5180-348.2182$

$0.6010 \quad-361.2258$

$0.5956-373.3276$

5.32

$0.5911 \quad-384.4594$ 
62.000 32558.60 9052.11

63.000 32786.91 8652.98

64.000 33002.39

8244.91

65.000

33206.38

7828.76

66.000

33398.99

7405.35

67.000

33580.32

6975.51

68.000

33751.02

6540.00

69.000

33911.66

6099.56

70.000

34062.22

5654.88

71.000

34204.27

5206.63

72.000

34337.15

4755.42

73.000

34461.58

4301.83

74.000

34578.65

3846.38

$$
-9.36
$$

459.19

9026.18
-59.18

234.6415

5.36

$-9.76$

461.02

8626.28
-61.14

221.8819

5.39

$-9.78$

462.82

8218.09
-62.97

209.6860

5.43

$-11.46$

464.53

7801.59

$-64.68$

197.9930

5.46

$-11.81$

466.08

7378.20

$-66.29$

186.7166

5.49

$-12.23$

467.45

6948.07

$-67.81$

175.8908

5.52

$-13.29$

468.60

6512.31

$-69.21$

165.5907

5.55

$-14.14$

469.50

6071.91

$-70.53$

155.7540

5.58

$-14.78$

470.15

5626.89

$-71.78$

146.3009

5.60

0.7809

$-427.0489$

$0.7194 \quad-420.2151$

$0.6756 \quad-412.5979$

$0.7194-420.2151$

0.7792

$-433.0966$

$0.7524 \quad-438.3679$

$0.8097 \quad-442.9160$

$0.8561-446.8079$

$-15.66$

470.54

5178.76

137.2792

$-72.94$

.5 .63

$-16.24$

470.66

4726.42

128.7621

$-74.03$

5.65

$-17.54$

470.53

4273.38

120.6701

$-75.05$

5.67

$-18.32$

470.15

3816.96

$-76.01$

112.9214

5.69
$0.8404 \quad-450.0639$

$0.8167 \quad-452.7091$

$0.8662-454.7908$

$0.9101 \quad-456.3917$ 


Applied Physics Laboratory
1.aturel. Narvland 20723-30y9!

\begin{tabular}{|c|c|c|c|c|c|}
\hline $\begin{array}{r}75.000 \\
34687.82 \\
3389.59\end{array}$ & $\begin{array}{r}-18.98 \\
469.53\end{array}$ & $\begin{array}{r}3360.84 \\
-76.91\end{array}$ & $\begin{array}{r}105.5723 \\
5.71\end{array}$ & 0.8866 & -457.5050 \\
\hline $\begin{array}{r}76.000 \\
34790.29 \\
2931.88\end{array}$ & $\begin{array}{l}-19.68 \\
468.68\end{array}$ & $\begin{array}{r}2902.46 \\
-77.75\end{array}$ & $\begin{array}{r}98.6748 \\
5.72\end{array}$ & 0.8540 & -458.1813 \\
\hline $\begin{array}{r}77.000 \\
34885.21 \\
2473.70\end{array}$ & $\begin{array}{l}-21.01 \\
467.62\end{array}$ & $\begin{array}{r}2443.80 \\
-78.54\end{array}$ & $\begin{array}{r}92.1650 \\
5.74\end{array}$ & 0.8981 & -458.4525 \\
\hline $\begin{array}{r}78.000 \\
34974.29 \\
2015.40\end{array}$ & $\begin{array}{l}-21.34 \\
466.37\end{array}$ & $\begin{array}{r}1985.56 \\
-79.28\end{array}$ & $\begin{array}{r}85.9400 \\
5.76\end{array}$ & 0.9393 & -458.3795 \\
\hline $\begin{array}{r}79.000 \\
35057.07 \\
1557.32\end{array}$ & $\begin{array}{l}-22.94 \\
464.96\end{array}$ & $\begin{array}{r}1526.90 \\
-79.99\end{array}$ & $\begin{array}{r}80.0816 \\
5.77\end{array}$ & 0.8987 & -458.0156 \\
\hline $\begin{array}{r}80.000 \\
35134.67 \\
1099.75\end{array}$ & $\begin{array}{l}-24.11 \\
463.40\end{array}$ & $\begin{array}{r}1069.77 \\
-80.63\end{array}$ & $\begin{array}{r}74.6423 \\
5.78\end{array}$ & 0.8785 & -457.3532 \\
\hline $\begin{array}{r}81.000 \\
35206.44 \\
642.96\end{array}$ & $\begin{array}{l}-24.30 \\
461.70\end{array}$ & $\begin{array}{l}613.08 \\
-81.25\end{array}$ & $\begin{array}{r}69.5039 \\
5.79\end{array}$ & 0.9269 & -456.4363 \\
\hline $\begin{array}{r}82.000 \\
35273.71 \\
187.17\end{array}$ & $\begin{array}{r}-25.54 \\
459.88\end{array}$ & $\begin{array}{l}156.78 \\
-81.83\end{array}$ & $\begin{array}{r}64.5989 \\
5.81\end{array}$ & 0.9463 & -455.3107 \\
\hline $\begin{array}{r}82.415 \\
35299.79 \\
-1.63\end{array}$ & $\begin{array}{l}-25.91 \\
459.08\end{array}$ & $\begin{array}{l}-31.66 \\
-82.06\end{array}$ & $\begin{array}{r}62.6715 \\
5.81\end{array}$ & 0.8887 & -454.7879 \\
\hline
\end{tabular}




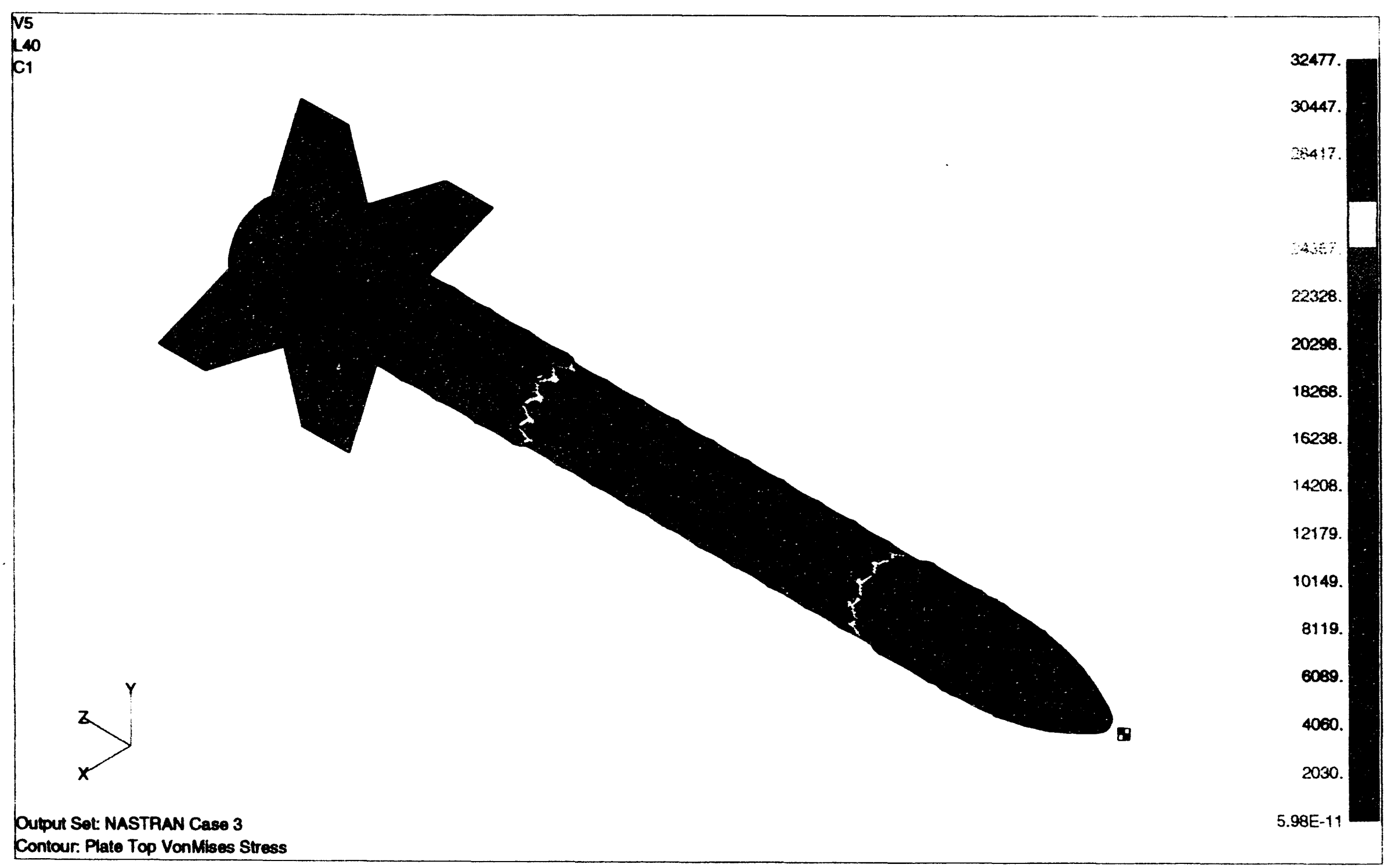

Figure 22 - Stress Contour Plot of ASTRID I Vehicle for Worst Case Flight Conditions (without wind gust loading) 


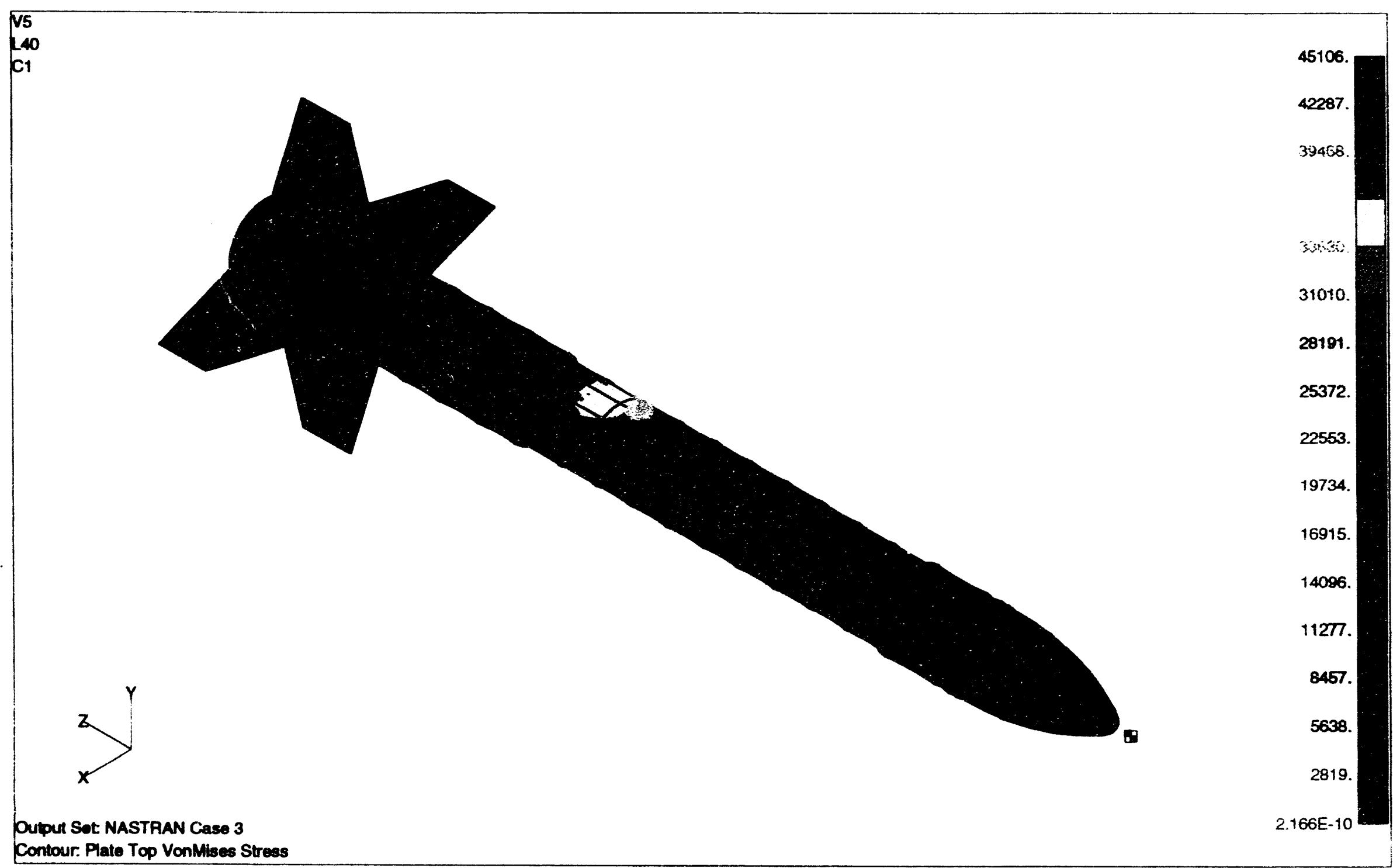

Figure 23 - Stress Contour Plot of ASTRID I Vehicle for Worst Case Flight Conditions (with wind gust loading) 

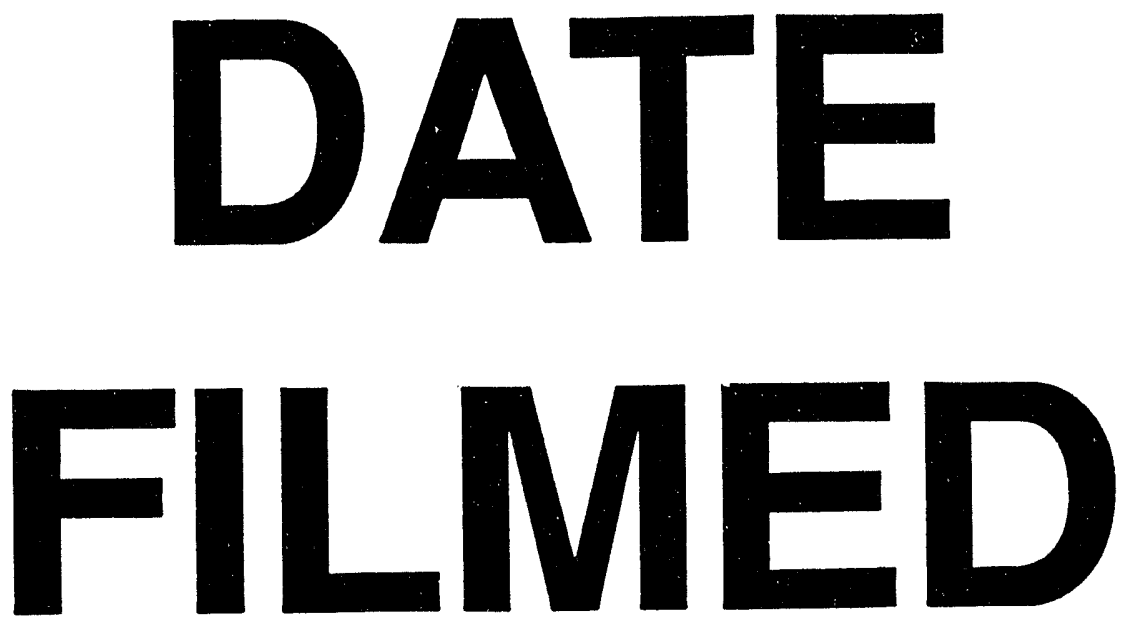

$8 / / 8 / 94$
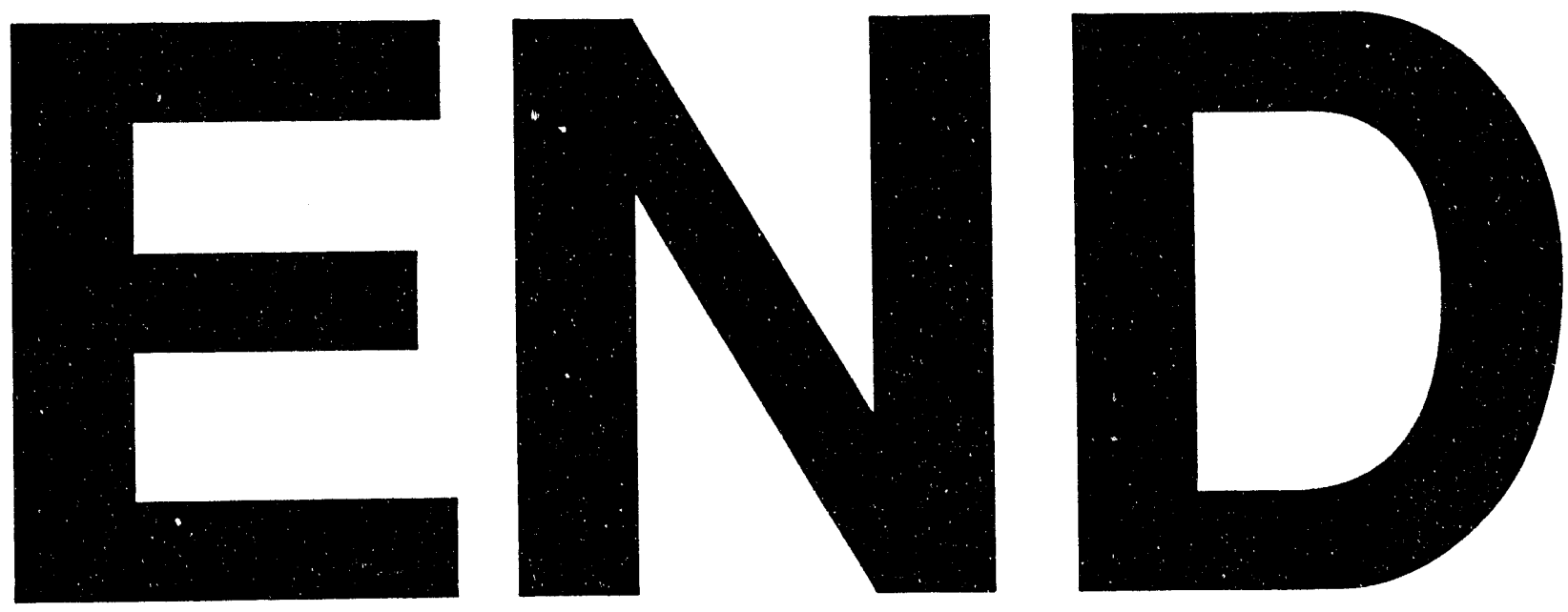


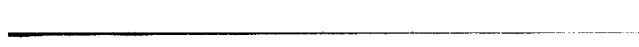

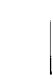

